ECCOMAS

Proceedia
COMPDYN 2021

$8^{\text {th }}$ ECCOMAS Thematic Conference on Computational Methods in Structural Dynamics and Earthquake Engineering

M. Papadrakakis, M. Fragiadakis (eds.) Streamed from Athens, Greece, 28 - 30 June 2021

\title{
SEISMIC PERFORMANCE ASSESSMENT OF AS-BUILT AND RETROFITTED RC BUILDINGS CONSIDERING THE INFLUENCE OF INFILLS: PRE-'70 LOW-MIDE RISE CASE-STUDIES
}

\author{
Maria T. De Risi ${ }^{1}$, Santa A. Scala ${ }^{1}$, Carlo Del Gaudio ${ }^{1}$, and Gerardo M. Verderame ${ }^{1}$ \\ ${ }^{1}$ University of Naples Federico II, \\ Department of Structures for Engineering and Architecture, \\ \{mariateresa.derisi, santaanna.scala, carlo.delgaudio, verderam\}@unina.it
}

\begin{abstract}
The seismic assessment and retrofit of non-conforming Reinforced Concrete (RC) buildings still represent a challenge for researchers and practitioners worldwide due to several aspects. On one hand, low standards RC buildings typically present some failure typologies very different from newly designed buildings, and such failure modes should be properly modelled for a reliable seismic performance assessment. On the other hand, retrofitting strategies should be chosen carefully looking both at safety at collapse and at seismic capacity at less severe performance levels, considering nonstructural components as well. Masonry infills, typically defined as non-structural components despite their structural role, significantly affect the seismic behavior of existing RC buildings, especially at low-medium intensity measures. Therefore, when the seismic performance of as-built or retrofitted $R C$ buildings is assessed, their contribution should be considered. In this work, a preliminary analysis of two 4-storey low-standard RC buildings, different for design typology, is presented, based on static nonlinear analyses. First, case-study buildings, representative of Italian pre-70 residential buildings, have been assessed in their "bare" configuration (without infills), as common in design practice, in a code-based approach (according to Italian code). Based on the asbuilt assessment outcomes, their retrofit has been designed by means of two main strategies: (1) the complete resolution of all the shear failures (in columns or joints), if any; (2) the reduction of the displacement demand by means of RC column jacketing, when necessary, along with the resolution of shear failures (as for the previous strategy). Then, both the as-built and retrofitted building configurations have been modelled and analysed explicitly considering the presence of infills and shear-critical elements. Fragility curves have been obtained at different Damage States according to European Macroseismic Scale EMS-98, considering record-to-record variability, and compared to each other. Remarks about the choice among strengthening strategies are carried out, based on these outcomes and on a preliminary estimation of the expected mean annual losses for the investigated buildings.
\end{abstract}

Keywords: RC buildings; damage states; masonry infills; strengthening; fragility curves; losses. 


\section{INTRODUCTION}

The seismic assessment and retrofit of non-conforming Reinforced Concrete (RC) buildings still represent a challenge for researchers and practitioners worldwide, due to several aspects.

On one hand, low standards RC buildings typically present some failure typologies very different from newly designed buildings [1]-[2], and such failure modes should be properly modelled for a reliable seismic performance assessment. In existing buildings, columns can likely suffer shear damage under seismic actions, due to the very poor concrete quality or the insufficient stirrups mechanical percentage, leading to reduced lateral displacement capacity, especially if shear failures are expected to occur before the member yielding ([1], [3]-[6]). Additionally, beam-column joints typically in low-standard buildings have been not designed at all and totally lack of stirrups. This means that shear failures in those connections could occur before the yielding of the adjacent members, thus limiting the overall ductility capacity of the whole building [7].

On the other hand, retrofitting strategies should be chosen carefully to comply with current codes, preventing the structural collapses (e.g. [1]). Nevertheless, in addition, a proper retrofit should also guarantee an reduction in expected annual seismic losses (e.g. [8]-[11]). To this end, the retrofit design should look at collapse safety and at seismic capacity at less severe performance levels as well. Especially at less severe performance levels, i.e. at more frequent seismic events, non-structural components must be considered. Among them, masonry infills, typically defined as non-structural components despite their structural role, significantly affect seismic performance and relevant losses in existing RC buildings, both as-built and retrofitted, as recently demonstrated by ([12]-[14]). Therefore, when seismic performance of retrofitted RC buildings is assessed, their contribution should be properly considered in numerical modelling and in damage and loss assessment.

In this work, a preliminary analysis of two case-study low-standard RC buildings, different for design typology, is presented, based on static nonlinear analyses. The investigated case-study structures are 4-storey buildings representative of Italian pre-70 residential buildings, designed for gravility loads only (GLD) or according to obsolete seismic design (OSD).

First, they have been assessed in their "bare" configuration (without infills), as typical in design practice. In such a first-step-assessment only nonlinear flexural response of beams and columns has been modelled, whereas columns/joints shear failures have been detected in post-processing, based on the current Italian code [15].

Then, based on the as-built assessment outcomes, the retrofit phase has been designed by means of two alternative strategies:

1. Strategy " $A$ ": the complete resolution of all the shear failures (in columns or joints), if any (by means, for example, of localised steel cages, pre-stressed steel strips or wrapping with Fiber Reinforced Polymers (FRP) fabrics);

2. Strategy " $B$ ": the reduction of the displacement demand by means of RC column jacketings, when necessary, along with the resolution of shear failures (as for the previous strategy).

These two strategies represent two boundary conditions for the retrofitted buildings since in strategy "A" no modification in the lateral stifness is produced, whereas strategy " $\mathrm{B}$ ", the most invasive one, necessarily leads to a higher lateral stiffness of the building.

Lastly, both the as-built and retrofitted building configurations have been modelled and re-analysed explicitly considering the presence of infills, and, in the case of as-built configurations, potential shear failures in columns/beams and joints. SPO analyses has been carried out and Incremental Dynamic Analyses (IDAs) curves have been derived by means of SPO2IDA tool [16]. Fragility curves have been finally obtained at different Damage States (DSs) according to European Macroseismic Scale EMS-98 [17], considering record-to-record variability, and compared to each other. Remarks about the choice of the stregnthening strategies are carried out, based on these oucomes and on a preliminar estimation of the expected mean annual losses for the investiagated buildings. 


\section{CASE-STUDY BUILDINGS}

In this work, two residential RC buildings are investigated as case-study structures. They have the same floorplan (see Figure 1a), symmetric in both directions. 4 meters length bays are present in both directions, except than the central bay, which has a length equal to 3 meters. The interstory height is $3 \mathrm{~m}$. In both cases, in the transverse direction, only two (external) frames are present, as typical for pre-70 existing buildings in Italy.

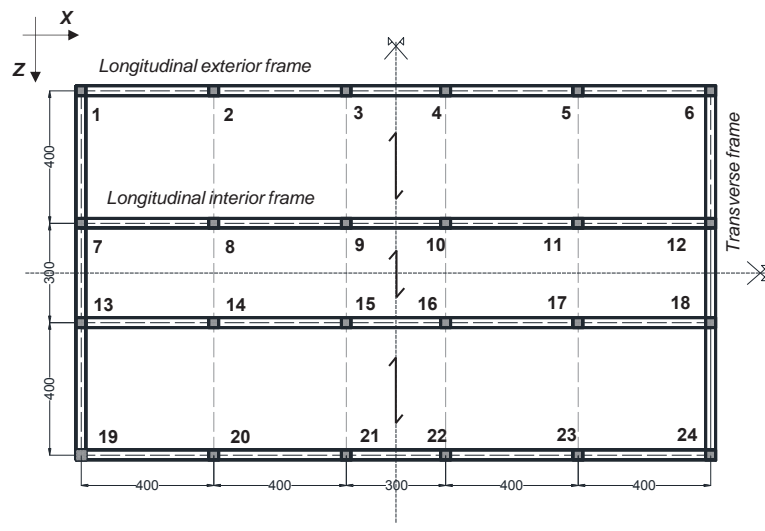

(a)

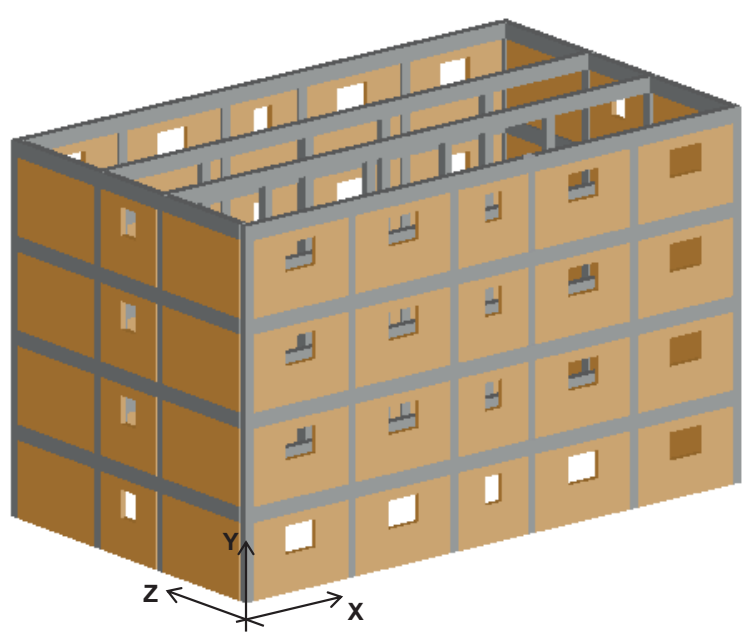

(b)

Figure 1: Plan view of the case-study buildings and column labels (a) (measures in centimetres); 3D view (b)

The two buildings differ to each other for the design typology. One building has been designed to sustain gravity loads only, as typical in Italy before ' 70 in most of the country. It will be referred to as Gravity Loads Designed (GLD) buildings. The other building has been designed according to an Obsolete Seismic Design (OSD) in force in Italy until the beginning of ' 70 and adopted for the (few) sites classified as seismic zone in that time period, as described later. Therefore, the investigated buildings are representative of the Italian building stock related to the same time period (between '50 and the very beginning of '70) but located in different sites (with different seismic hazard at the year of construction), as explained in section 2.1.

\subsection{Location and seismic hazard}

Both the considered buildings are in medium-high seismic hazard sites in Italy. The GLD building is located at Morra de Sanctis, in the Southern of Italy. Such location has been classified as a seismicprone site only after the well-known Irpinia earthquake (1980) and, therefore, all the buildings realized before ' 80 have been designed to sustain gravity loads only.

The OSD building is assumed to be located in L'Aquila city (Abbruzi region, Italy), which has been classified as seismic-prone starting from the very beginning of the last century, and, thus, the major part of its existing RC buildings has been designed to take into account seismic actions, according to seismic prescriptions as obsolete as their age of construction.

Figure 2a shows the location of these two sites on the current seismic Italian hazard map by the National Institute of Geophysics and Vulcanology (INGV) in terms of expected ground acceleration with a $10 \%$ probability of exceedance in 50 years. Additionally, Figure $2 \mathrm{~b}$ reports a comparison between the pseudo-accelerations $\left(\mathrm{S}_{\mathrm{a}}(\mathrm{T})\right)$ of the two selected sites at different return period $\left(\mathrm{T}_{\mathrm{R}}\right)$ corresponding to four limit states according to Eurocode 8-part 1 [18] and Italian code [15] 
(Immediate Occupancy, $\mathrm{T}_{\mathrm{R}}=30 \mathrm{y}$; Damage Limitation, $\mathrm{T}_{\mathrm{R}}=50 \mathrm{y}$; Life-Safety, $\mathrm{T}_{\mathrm{R}}=475 \mathrm{y}$; Near Collapse, $\left.\mathrm{T}_{\mathrm{R}}=975 \mathrm{y}\right)$.

In both cases, it is assumed soil type "C" and soil topography "T2" [18] for the definition of the local seismic amplification effects.

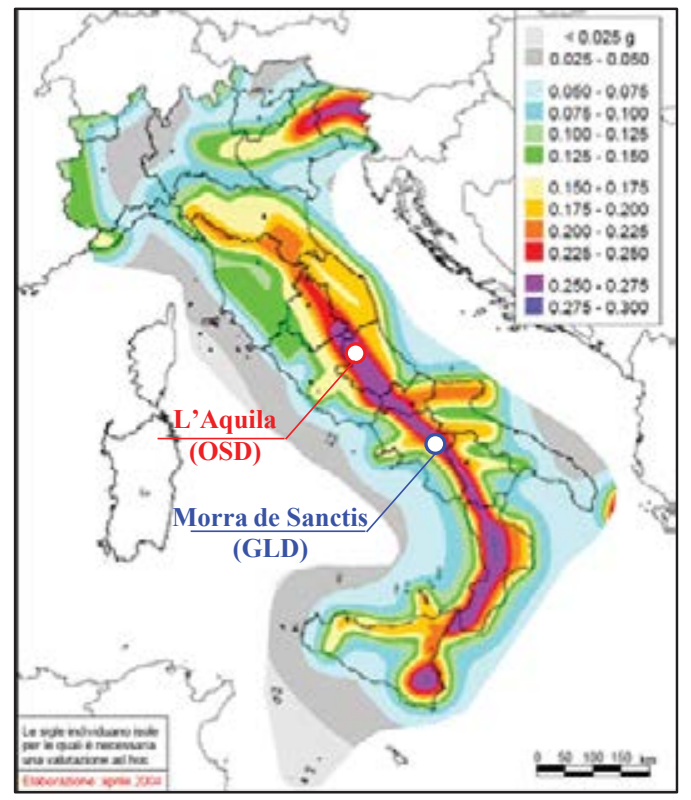

(a)

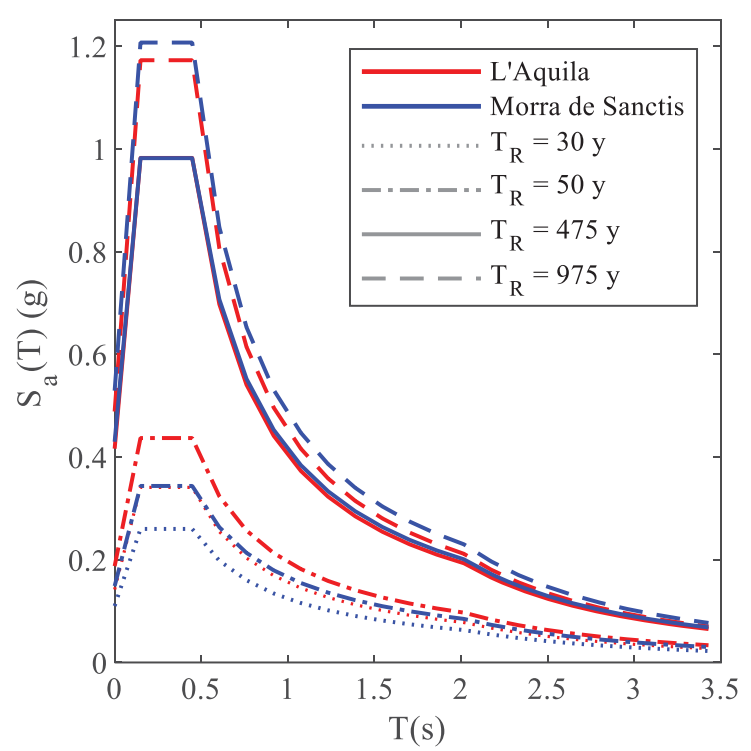

(b)

Figure 2: Buildings locations on the current hazard map by the National Institute of Geophysics and Vulcanology

(INGV) (a); comparisons among pseudo-acceleration $(\mathrm{Sa}(\mathrm{T}))$ spectra at different return periods $\left(\mathrm{T}_{\mathrm{R}}\right)(\mathrm{b})$

\subsection{Simulated design}

The moment resisting frames (MRFs) system for both the buildings is characterized by 2D resisting frames in the longitudinal (X) direction, whereas, in the transverse $(\mathrm{Z})$ direction, MRFs are present only along the exterior perimeter. Floors are $20 \mathrm{~cm}$ thick, with $4 \mathrm{~cm} \mathrm{RC} \mathrm{slab.} \mathrm{As} \mathrm{shown} \mathrm{in}$ Figure 1a, the floor weight is sustained by the longitudinal frames only. Infills differ between the two directions for the openings presence: the opening percentage ranges from 0 to $15 \%$ of the infill total area, as qualitative shown in Figure 1b. An infill weight (per panel unit surface) equal to $2.00 \mathrm{kN} / \mathrm{m}^{2}$ and $2.36 \mathrm{kN} / \mathrm{m}^{2}$ for longitudinal and transverse direction, respectively, is assumed for exterior frames. "Maximum allowable stress method" is adopted for the "simulated design" of these buildings [19]. Since all the buildings were "located" in the same time period, the design mechanical properties of reinforcing steel and concrete are identical for all the buildings. Maximum allowable concrete strength was assumed equal to $5 \mathrm{MPa}$ or $6 \mathrm{MPa}$, for purely compressive loads or bending actions, respectively (according to [21]). A maximum allowable strength equal to $140 \mathrm{MPa}$ has been adopted for reinforcing bars [21] in the hypothesis that steel typology "AQ42" was used, as typical in the reference time period in Italy [20]. It is worth noting that plain bars were used as reinforcement typology, as typical in pre-'70 RC buildings in Italy ([20], [22]).

Additionally, infill panels are supposed to be identical for both the analysed buildings, and in particular made up of hollow clay bricks assembled with mortar: the presence of two coupled leaves is assumed, with $120 \mathrm{~mm}$ and $80 \mathrm{~mm}$ thickness, respectively, as typical in Italian and Mediterranean area in the reference time period [23].

GLD buildings have been designed to sustain gravity loads only and to comply code prescriptions about minimum amount of longitudinal and transverse reinforcement as defined by the Italian R.D. 
[21]. On the contrary, OSD buildings are designed to sustain horizontal loads, too, the latter defined according to obsolete seismic codes in force in the reference time period ([24]-[25]), which allowed modelling the seismic actions as horizontal equivalent forces constant along the building height. The design horizontal acceleration was equal to 0.07 times the gravity acceleration ([24]-[25]). Additionally, the total design base shear is divided among resisting frames proportionally to the vertical loads supported by each of them, as typical for the reference time period. This means that transverse frames should support very low lateral actions, whereas longitudinal interior frames should sustain the highest horizontal loads. As a result, transverse frames are almost identical between GLD and OSD buildings; whereas, longitudinal frames generally result in a higher reinforcement amount, especially at the lowest stories (where columns have the highest longitudinal reinforcement percentage). The reinforcement percentage values of the first-floor columns significantly decrease at the upper stories (varying around about $0.7 \%$ ). Stirrups with $250 \mathrm{~mm}$ maximum spacing and $8 \mathrm{~mm}$ diameter have been used in the beams; stirrups with $140 \mathrm{~mm}$ spacing and $6 \mathrm{~mm}$ diameter have been used in the columns (in agreement with prescriptions by [21]). All the beams resulted in a $30 \times 50 \mathrm{~cm}^{2}$ cross-section, whereas column sections vary from a minimum of $30 \times 30 \mathrm{~cm}^{2}$ (for most of the columns) to a maximum of $30 \times 40 \mathrm{~cm}^{2}$ (for central columns). Rectangular columns are always oriented in the longitudinal direction. Further details can be found in [26].

\subsection{Material properties}

Lastly, a key issue for the complete assessment and modelling of the case-study structures is the definition of the strength values used for concrete, steel and infills.

As far as the as-built buildings is concerned, mean values of concrete compressive strength $\left(f_{c}\right)$ and reinforcing yielding strength $\left(\mathrm{f}_{\mathrm{y}}\right.$ ) have been assumed equal to $20.0 \mathrm{MPa}$ and $322.4 \mathrm{MPa}$, respectively, according to suggestions by [27] and [20] for the adopted steel typology and the reference time period. Infill panels are characterized by a diagonal compressive strength $\left(\tau_{\mathrm{cr}}\right)$ equal to $0.27 \mathrm{MPa}$ and a Young modulus (parallel to the holes) of $3000 \mathrm{MPa}$. Such values are based on a subset of data collected in [28] on weak Italian infills characterised by horizontally placed hollow clay bricks with a void percentage of about $60 \%$, as typical of the investigated case-study buildings. It is worth noting that the definition of infill mechanical properties is a complex issue, since they are characterised by a very high variability and they significantly depend on brick typology and strength, mortar mechanical properties, bricks void percentage, bricks compressive strength. Therefore, a further extension of the present work should explicitly consider the possible variability of the key infill mechanical properties and their effect on structural response (e.g. [29]).

\section{CODE-BASED ASSESSMENT AND DESIGN OF RETROFIT}

This section shows the first-step seismic assessment of the two case-study buildings, performed according to the current Italian code [15]. A "Normal Knowledge Level" (KL2) ([15], [30]) has been assumed; therefore, according to [15], the mean values of the mechanical properties of existing materials used in the capacity calculation have been divided by a confidence factor equal to 1.20. Two performance levels have been analysed for this code-based assessment: "Damage Limitation" (DL) and "Life Safety" (LS) limit states, corresponding to seismic actions with a return period of 50 and 475 years, respectively ([15], [30]). The building's capacity at DL limit state is assumed to be achieved when for the first time an inter-story drift ratio (IDR) equal to $0.5 \%$ is achieved. The LS limit state is reached when for the first time a member achieves a chord-rotation equal to $3 / 4$ of the ultimate rotation $\left(\theta_{\mathrm{u}}\right)$ (flexural failure) or when a shear failure arises (in beams, columns, or joints), as explained in this section. Demand-to-capacity peak ground acceleration (PGA) ratio for each considered limit state represents the building's safety index (SI) at that limit state. Thus, the design of retrofit has been carried out based on this index, as explained in detail in the next sub-sections. 


\subsection{Modelling assumptions}

The seismic response of the investigated case-study buildings has been numerically reproduced in OpenSees platform [31] and analysed by means of nonlinear static pushover (SPO) analyses in N2 framework [32], according to the modelling assumptions explained herein. In particular, a lumped plasticity approach has been used for RC members by means of zero-length elements in OpenSees located at the ends of each beam/column element in series with elastic BeamColumn elements (see Figure 3).

First of all, for this code-based assessment and the relevant design of retrofit intervention, the buildings have been modelled as "bare frames", namely, infills are not included in the numerical models, unless in the definition of masses and loads, as usual in common practice approaches. Additionally, the "code-based" numerical models only reproduce the nonlinear flexural response of the RC members; therefore, static pushover curves are derived in the hypothesis that all the elements are "ductile" members.

For elements with plain bars, the flexural (bending moment, $\mathrm{M}$ - versus - chord rotation, $\theta$ ) response of beams and columns has been modelled by means of the (quadri-linear) proposal by [22], calibrated for RC elements reinforced with plain bars, and implemented in the adopted software with a ZeroLength Elements (Figure 3) characterised by the Pinching4 uniaxial material. The four-point envelope represents: the yielding point ("y"), the capping point ("cap"), the softening branches" intersection ("int"), the zero-strength condition (" 0 "). Such material has been slightly modified by adding an additional point corresponding to the first cracking ("cr") point (Figure 3).

Lastly, floors are assumed to be stiff in their own plane.

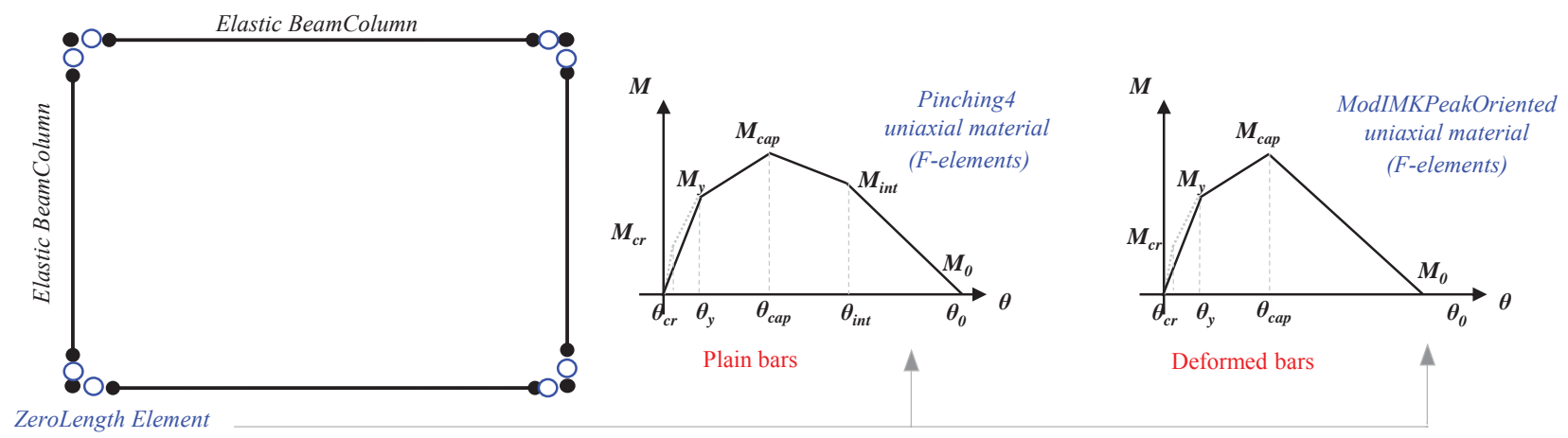

Figure 3: Schematic view of the modelling adopted for each bay in a code-based approach

In this code-based assessment phase, ductile members reach their capacity at the LS Limit State [18] when their chord rotation demand reaches $3 / 4$ of the ultimate chord rotation capacity $\left(\theta_{u}\right)$, the latter assessed according to the proposal by [33], as suggested by the Eurocode 8 [18] and the Italian prescriptions [34].

Nevertheless only the flexural response is modelled, as explained before, eventual shear failures in columns/beams or joints have been detected by means of a post-processing of the static pushover results, as common in practice. To this end, the Italian code-prescriptions have been adopted, so that:

- joint shear failure occurs when its principal compressive stress, $p_{c}$, overcomes 0.5 times the concrete compressive strength, $f_{c}$, or if the principal tensile stress, $p_{t}$, overcomes 0.3 times the square root of $f_{c}$ [34], based on suggestions by [35] and limiting the joint failure to its shear cracking (each further strength mechanism beyond the shear cracking is neglected by this code); 
- columns/beams shear failure occurs when the demand shear load overcomes the shear strength, the latter evaluated according to the model by [36] as suggested by the Eurocode 8 [18] and [34], and thus depending on the inelastic displacement demand.

\subsection{As-built assessment according to Italian (D.M. 2018) code}

SPO analyses have been performed separately in longitudinal (X) and transverse (Z) directions. Two lateral load patterns have been used: (i) (pseudo-)"Uniform" pattern, proportional to the storey mass distribution, and (ii) "Modal" pattern, proportional to the first-mode deformed shape in the considered direction, according to Italian prescriptions [15].

Figure 4 shows the resulting SPO curves in terms of top displacement $\left(\Delta_{\text {top }}\right)$ - versus - base shear, along with the achievement of the first joint cracking, the first shear failure in RC members, the first "ductile" failure (chord rotation demand reaches $3 / 4 \theta_{\mathrm{u}}$ ), and the capacity point at the DL limit state, for GLD and OSD case-study buildings. SPO curves of OSD building generally present in the longitudinal direction higher base shear values and displacement capacity with respect to GLD building; conversely, SPO curves in the transverse direction are quite similar to each other, mainly due to the very low difference in geometry and reinforcement amount in that direction (as a consequence of the simulated design, as explained in section 2). A global collapse mechanism is observed in the transverse direction for both the case-study buildings and for both the lateral load patterns; whereas local mechanisms are observed in the longitudinal direction. In particular, for the GLD building local first- and second-floor mechanisms are observed applying respectively the "Uniform" and the "Modal" distributions; for OSLD building a second- and third-floor mechanism are observed.

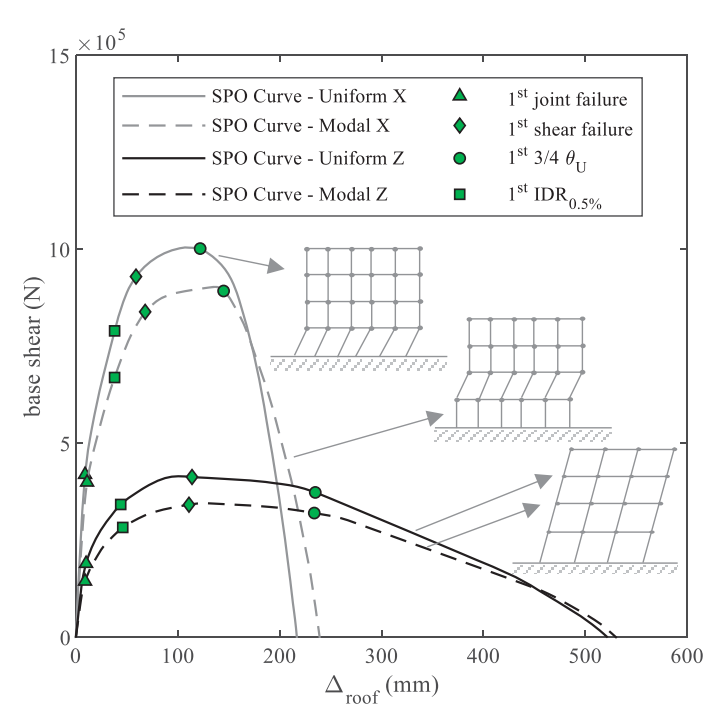

(a)

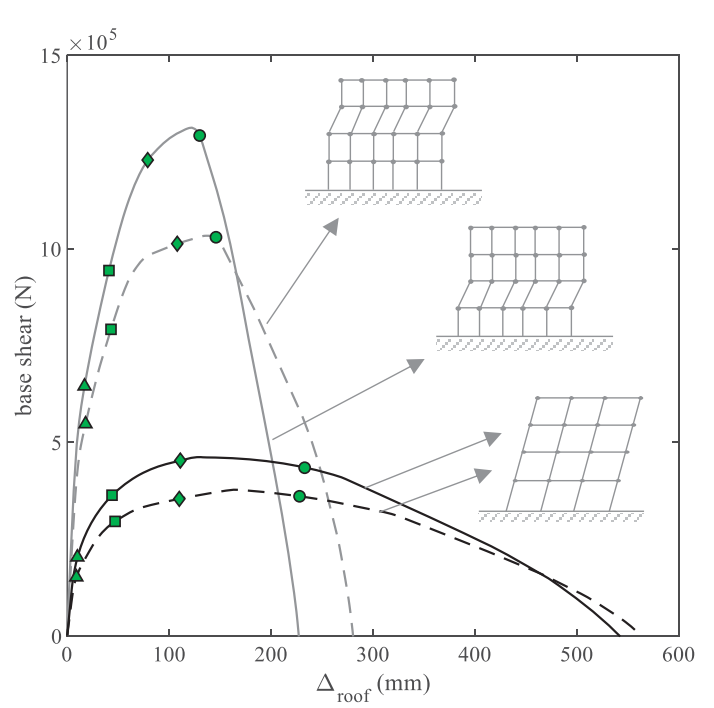

(b)

Figure 4: Static Pushover curves for (a) GLD and (b) OSD case-study buildings

Starting from each SPO curve (SPC), the capacity curve (CC) of the equivalent single-degree-offreedom (SDOF) system [32] can be obtained dividing the abscissa and ordinates of SPO curve by the first modal participation factor in the considered direction (see Figure 5a). The CC has been bilinearized using an equal-energy approach (according to [15]) thus obtaining an Elastic-PerfectlyPlastic (EPP) curve (whose first elastic branch is characterised by an "effective" period, Teff). The EPP curve is, then, represented in the Acceleration-Displacement Response Spectrum (ADRS) 
domain, where also the demand spectrum at the considered limit state can be reported (see Figure $5 b)$.

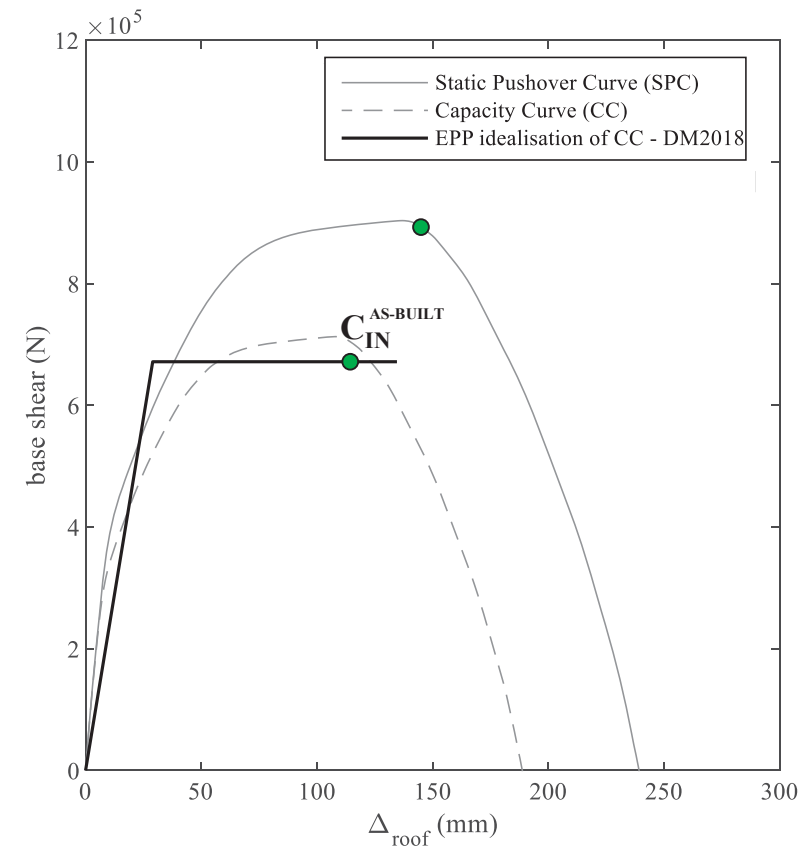

(a)

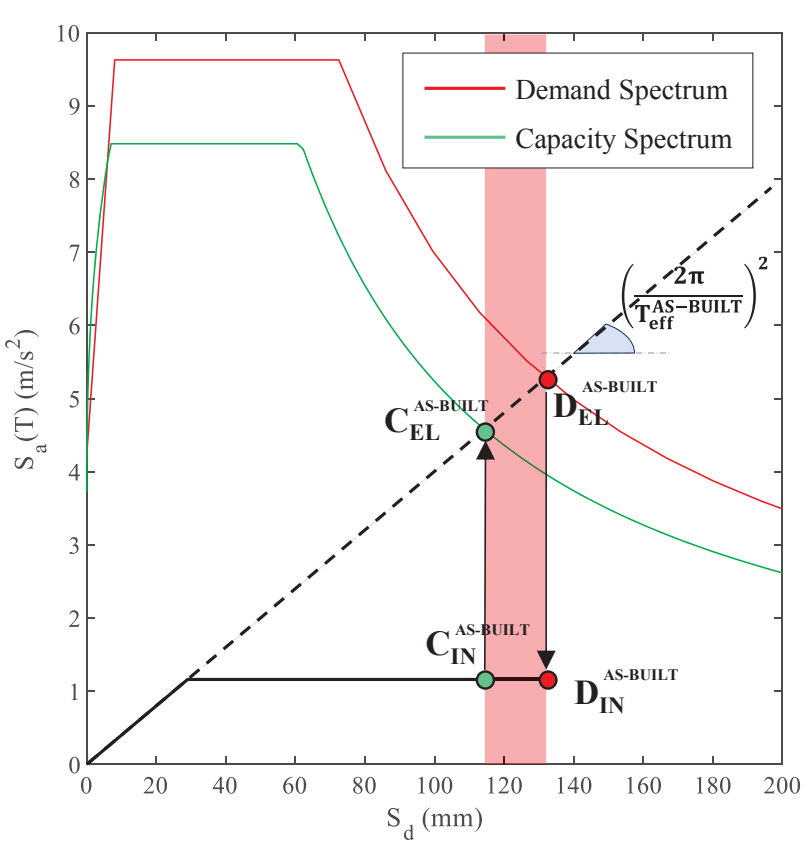

(b)

Figure 5: Example of the seismic assessment procedure: from the SPO curve to EPP capacity curve (a); from the EPP capacity curve to the capacity spectrum (b)

In order to obtain the "capacity spectrum" for a given capacity point, the elastic capacity point (i.e., $\mathrm{C}_{\mathrm{EL}}{ }^{\text {As-built }}$ for the as-built configuration) should be detected starting from the corresponding inelastic capacity point $\left(\mathrm{C}_{\mathrm{IN}}{ }^{\mathrm{As}-b u i l t}\right)$, using the equal displacement rule, modified for short period systems by [37]. In particular, in case of long or intermediate effective period of the equivalent $\operatorname{SDOF}\left(\mathrm{T}_{\mathrm{eff}} \geq \mathrm{T}_{\mathrm{c}}\right)$, the elastic and the inelastic displacements (i.e., the abscissas of $\mathrm{C}_{\mathrm{EL}}{ }^{\text {As-built }}$ and $\mathrm{C}_{\mathrm{IN}}{ }^{\mathrm{As}-\text { built }}$ points) match each other, whereas the ordinate of $\mathrm{C}_{\mathrm{EL}}{ }^{\text {As-built }}$ point can be graphically obtained by intersecting the vertical line through $\mathrm{C}_{\mathrm{IN}}{ }^{\mathrm{As}-\mathrm{built}}$ with the elastic branch of the bi-linearization. The resulting spectrum passing by $\mathrm{CEL}^{\text {As-built }}$ is the capacity spectrum at the considered limit state, to be compared with the demand spectrum at the analysed limit state. In particular, the demand-to-capacity ratio in terms of PGA is defined herein as the building's safety index (SI), based on which the design of retrofit has been carried out.

In Figure 6 the above-explained seismic assessment procedure is shown for the (i) DL limit state, and the (ii) LS limit states (at the achievement of the first ductile failure (DF)), for GLD and OSD casestudy buildings, separately in longitudinal $(X)$ and transverse $(Z)$ directions.

Quite low SI values have been obtained at DL limit state, especially in the Z direction, being SIDLLS equal to 0.63 and 0.50 , for GLD and OSLD buildings, respectively.

For both the buildings and in both directions, the safety index at LS limit state (SILSLS,DF) is quite high, if only ductile failures are considered (especially for the OSLD case-study building). Nevertheless, when shear failures are considered, too, at LS limit state, the SIs values significantly decrease, as reported in Table 1, which shows also the resulting SIs in terms of PGA at the first joint cracking and at the first shear failure in $\mathrm{RC}$ beams/columns for each direction and for both case-study buildings. Note that, for the first joint failure, in both directions the same SI is observed, being the corresponding capacity return periods less than 30 years for both the main directions. Thus, for both directions, the same "minimum" code-based [15] spectum has been considered as capacity spectrum 
$\left(T_{R}=30 y\right)$. Based on these outcomes, the retrofit of the two case-study buildings has been designed by means of two main strategies, as explained in the next sub-section.

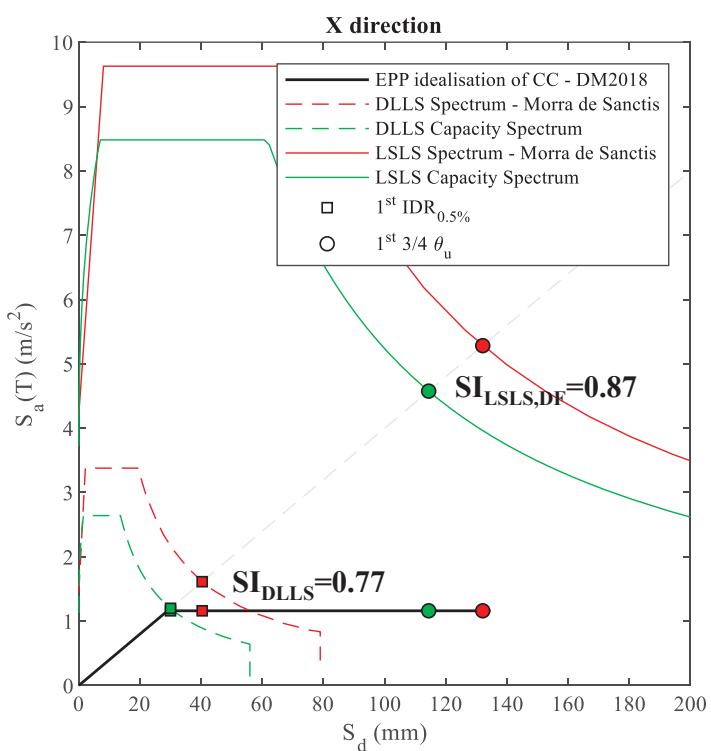

(a)

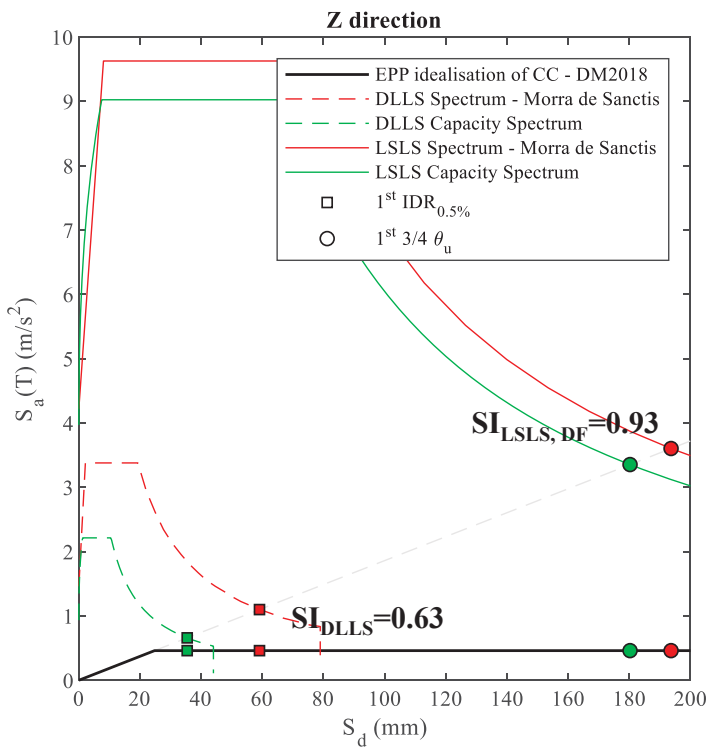

(c)

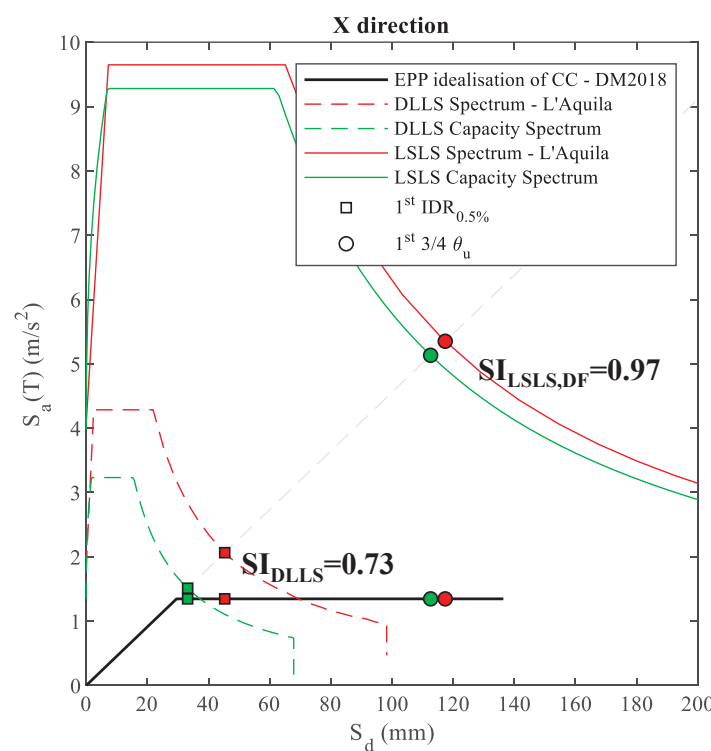

(b)

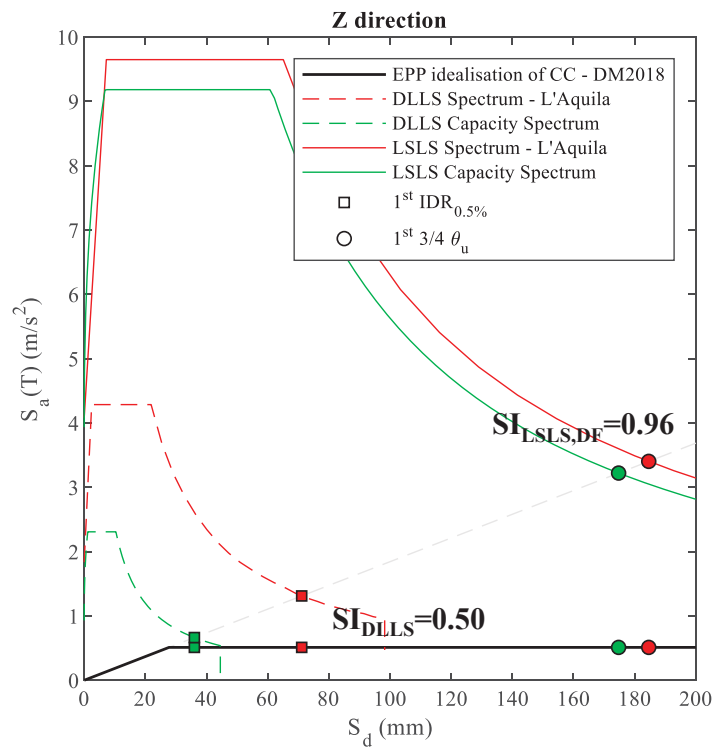

(d)

Figure 6: Seismic assessment with reference to Damage Limitation (DL) and Life Safety (LS) limit states for (a; c) GLD and (b; d) OSD case-study buildings

\begin{tabular}{|c|c|c|c|c|}
\hline & \multicolumn{2}{|c|}{ GLD } & \multicolumn{2}{c|}{ OSD } \\
\hline & X direction & Z direction & X direction & Z direction \\
\hline $\mathbf{1}^{\text {st }} \mathbf{I D R}=\mathbf{0 . 5 \%}$ & 0.77 & 0.63 & 0.73 & 0.50 \\
\hline $\mathbf{1}^{\text {st }}$ joint failure & 0.34 & 0.34 & 0.19 & 0.19 \\
\hline $\mathbf{1}^{\text {st }}$ shear failure & 0.62 & 0.52 & 0.43 & 0.47 \\
\hline $\mathbf{1}^{\text {st }}$ ductile failure & 0.87 & 0.93 & 0.93 & 0.96 \\
\hline
\end{tabular}

Table 1: SIs summary

\subsection{Design of retrofit}


The main aim of the design of the retrofit strategies is to increase the SI towards/beyond the unity, by adopting one of the available retrofitting techniques or also combining them. Mainly, these techniques are based on strategies which involve the reduction of the seismic demand or/and the increase of the building's capacity. In this work, two main strategies for the retrofit's design have been considered:

(A) the complete resolution of all the shear failures (in columns or joints) only, by means, for example, of localised wrapping with Fiber Reinforced Polymers strips, steel cages, or prestressed steel strips;

(B) the reduction of the displacement demand at DL limit state by means of RC column jacketings, when necessary, along with the resolution of shear failures (as for the strategy A).

Strategy "A" aims at the resolution of all the shear failures, both in joints and shear-critical columns, by means localised interventions. According to this strategy (see Figure 7a), any shear failure in the post-retrofit phase is solved, so that the seismic capacity moves from the first shear failure of joint the minimum one in the as-built configuration - (at $\mathrm{J}^{\mathrm{As} \text {-built }}$ in Figure $7 \mathrm{a}$ ) to the first ductile failure (at $\mathrm{C}_{\mathrm{IN}}{ }^{\text {As-built }}$ ). This strategy does not reduce the seismic displacement demand (being $\mathrm{T}_{\text {eff }}{ }^{\text {As-built }}$ $=\mathrm{T}_{\text {eff }}^{\text {Retrofit }}$, but only increases the shear capacity and, in tune, the deformation capacity of the retrofitted members. As a result, the final SI of the building is not higher or equal to the unity, but it corresponds to the first ductile failure capacity (which in these cases is always beyond the $80 \%$, namely already "acceptable" according to current codes [15]). Such strategy could be pursued by means of FRP fabrics, steel cages or pre-stressed steel strips. However, note that the exact definition of the tecnique and the material properties to be used to apply this strategy is beyond the scope of this work.

Conversely, strategy " $\mathrm{B}$ " is based on the decrease of the seismic demand of the entire structure by means of the increase of building's stiffness. In Figure $7 b$, the retrofit strategy " $B$ " is graphically shown, starting from the elastic demand point in the as-built condition ( $\mathrm{DeL}_{\mathrm{Es}}^{\mathrm{As}-b u i l t}$ ). This point belongs to the demand spectrum at the considered limit state and can be detected considering the effective period of the equivalent SDOF ( $\left.\mathrm{T}_{\text {eff }}{ }^{\text {As-built }}\right)$. The corresponding inelastic demand ( $\left.\mathrm{D}_{\mathrm{IN}}{ }^{\text {As-built }}\right)$ can be found though the equal displacement rule. Therefore, to achieve SI equal to one, the retrofit intervention should be able to move the inelastic demand from $\mathrm{D}_{\mathrm{IN}}{ }^{\text {As-built }}$ to $\mathrm{C}_{\mathrm{IN}}{ }^{\mathrm{As}-b u i l t}$, reducing the effective period of the equivalent SDOF. This strategy may be implemented by using the RC jacketing, making an additional concrete layer outside the perimeter of the existing members, and introducing additional longitudinal and transversal reinforcements. For both the buildings, RC column jacketing are designed by assuming as $\mathrm{C}_{\mathrm{IN}}{ }^{\text {As-built }}$ the capacity at DL limit state, instead than the first ductile failure at LS limit state. It is worth noting that in a code-based approach, the safety check at DL limit state is not mandatory [15], but in this study it has been analysed to create an upper bound for the lateral stiffness that can be reached for these buildings. For both the buildings, the retrofit's designed involved the columns belong to the MRFs along the exterior perimeter in $\mathrm{Z}$ direction (see Figure 8). The concrete overlay of the four-sided jacket is at least $100 \mathrm{~mm}$, to guarantee a sufficient cover for the new reinforcement. In particular, all the jacketed columns resulted in a 50x60 $\mathrm{cm}^{2}$ cross-section (starting from the original $30 \times 30 \mathrm{~cm}^{2}$ ) for GLD building and in a $50 \times 70 \mathrm{~cm}^{2}$ crosssection (starting from $30 \times 30 \mathrm{~cm}$ for the corner's columns and $40 \times 30 \mathrm{~cm}$ for the remaining ones) for OSD building. The jacket's concrete class and the reinforcement steel type is $\mathrm{C} 25 / 30\left(\mathrm{f}_{\mathrm{ck}}=25 \mathrm{MPa}\right.$; $\left.\mathrm{f}_{\mathrm{cm}}=33 \mathrm{MPa}\right)$, and $\mathrm{B} 450 \mathrm{C}\left(\mathrm{f}_{\mathrm{yk}}=450, \mathrm{f}_{\mathrm{ym}}=500 \mathrm{MPa}\right)$ respectively [18]. The longitudinal reinforcement is $12 \Phi 18$ and $12 \Phi 20$ (i.e., about $1 \%$ of the new cross-section area) for GLD and OSLD buildings, respectively. Additionally, stirrups with $140 \mathrm{~mm}$ spacing and $8 \mathrm{~mm}$ diameter have been used in both buildings; they were designed to guarantee a ductile behaviour for these new columns. 


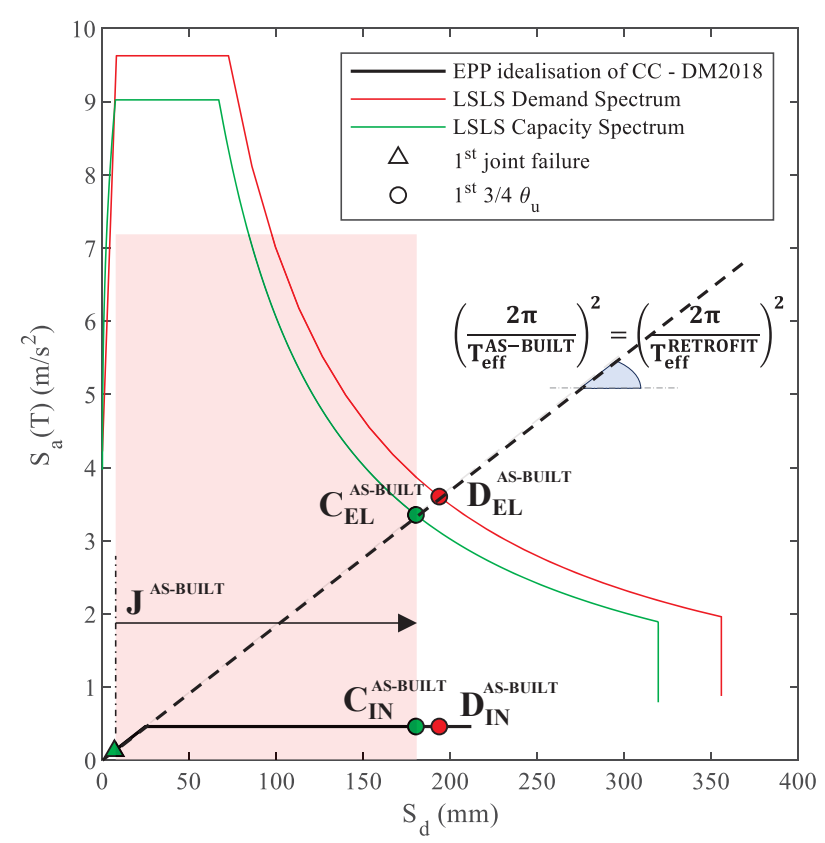

(a)

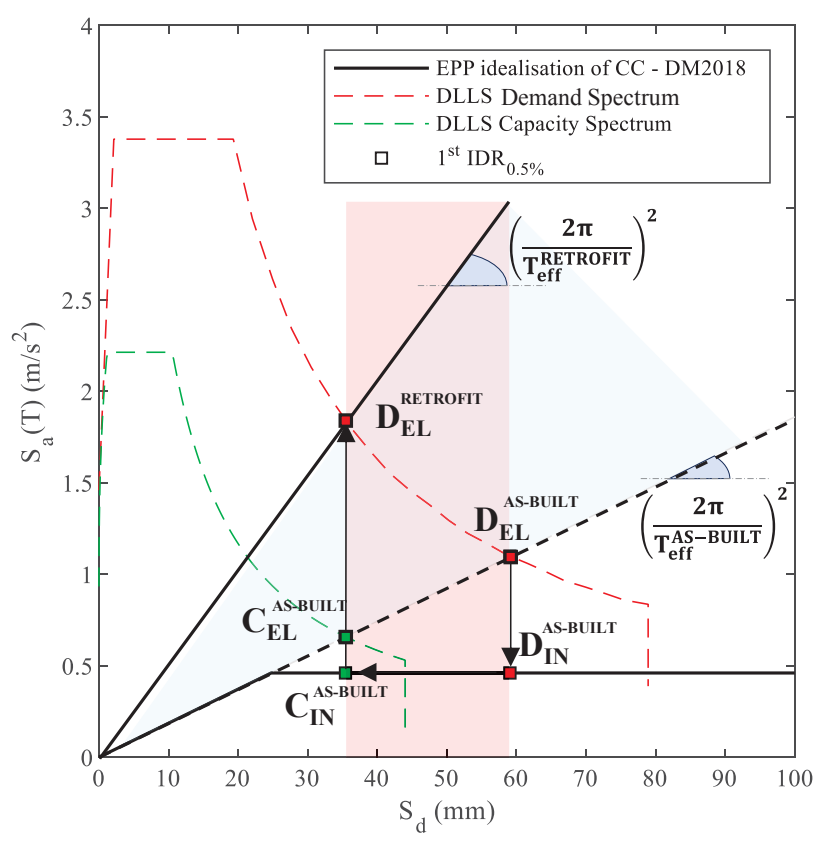

(b)

Figure 7: Strategies "A" (a) and "B" (b) for buildings' retrofit in the ADRS domain.

These retrofit solutions allow to increase the safety indexes.

If Strategy "A" is applied, SI at LS limit state increases from 0.34 to 0.87 for the GLD building, and from 0.19 to 0.93 for the OSD building (see Table 1); the re-analysis of the retrofit buildings is not necessary since no modification in mass and stiffness are expected to occur if this strategy is applied [38]. Additionally, DL limit state safety check does not change at all, obviously.

On the contrary, if Strategy "B" is applied, the retrofitted buildings should be re-modelled and reanalysed to prove its effectiveness. In this case, for member with deformed bars, namely only for columns interested by RC jacketing in the retrofitted buildings, the nonlinear flexural response has been modelled by means of the proposal by [39]. Note that, for sake of simplicity, and according to Italian code [15], it is assumed that the "new" jacketed" sections are made up of the new steel and concrete only, and that the whole new section will sustain the total axial load (including gravity loads already present in the as-built phase). The "shape" of the moment-rotation relationship of the nonlinear response used for these elements is similar to that already described for members with plain bars, except than for the softening phase, as shown in Figure 3. It is worth noting, however, that an important difference exists between the models used herein for members with plain bars and with deformed bars: the model by [22] proposes a monotonic backbone that already reproduces the envelope of the cyclic response of columns subjected to cyclic lateral loading; on the contrary, the monotonic curve provided by [39]'s model does not account for any cyclic degradation, and some degrading rules have been suggested explicitly depending on the case-specific loading history. Such a discrepancy should be necessarily solved in future works, if a comparison based on static pushover curves has to be performed. With these modelling hypotheses, Figure 9 (a,b) shows the SIs in $\mathrm{Z}$ direction (the direction that conditioned the design of retrofit) for the buildings retrofitted by means of the Strategy "B", highlighting a great reduction in the effective period of the equivalent SDOF, and resulting in $\mathrm{SI}_{\text {DLLS }}$ very close to the unity for both the buildings. 


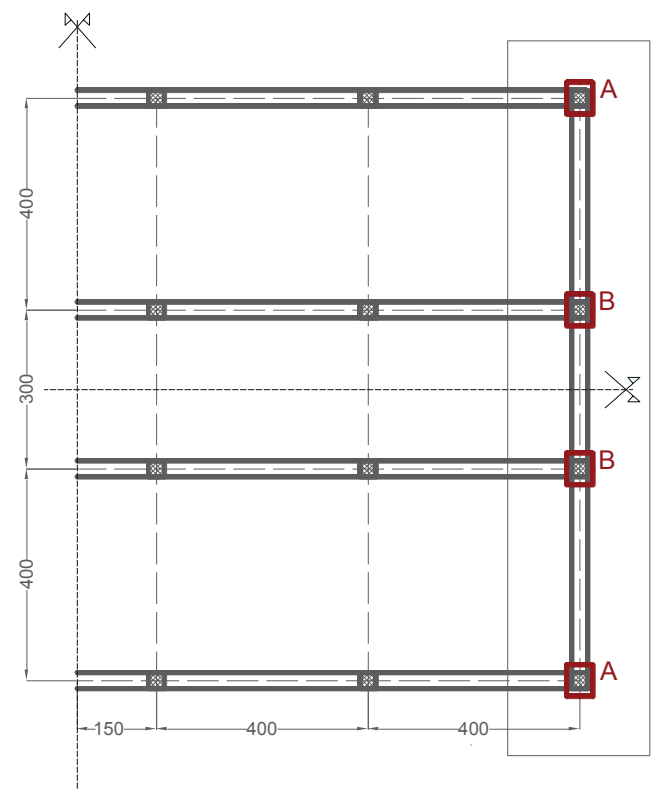

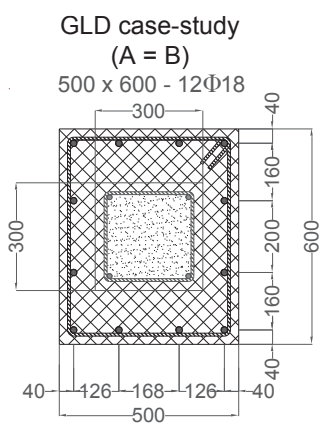

OSLD case-study
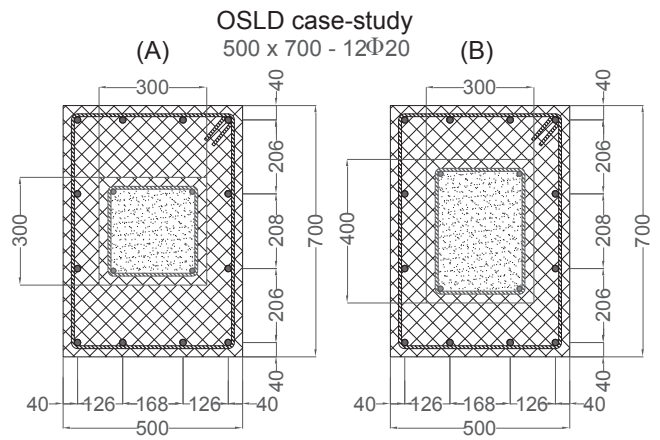

dimensions in $\mathrm{mm}$

Figure 8: RC jacketing defined according to Strategy "B"

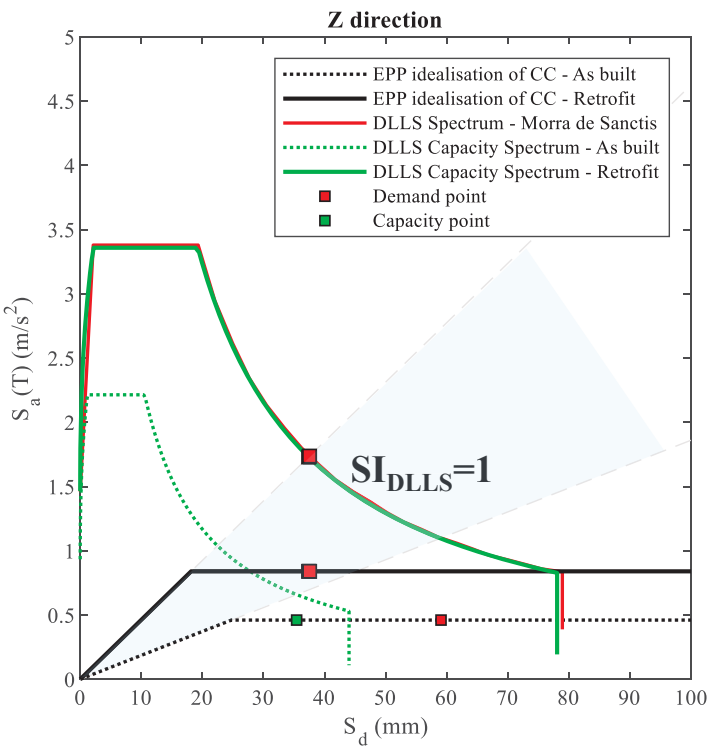

(a)

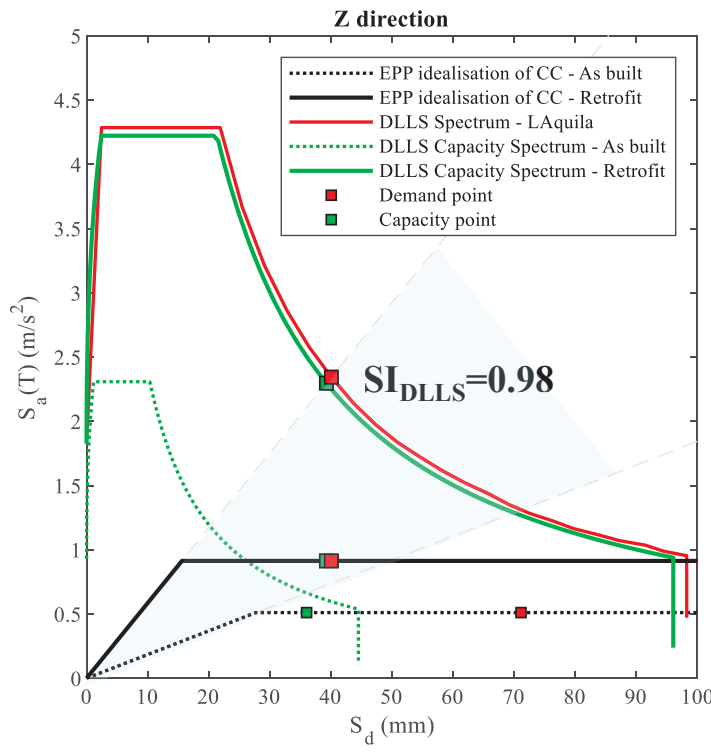

(b)

Figure 9: Seismic assessment with reference to Damage Limitation (DL) limit state for as-built and retrofitted (a) GLD and (b) OSD buildings

\section{RE-ASSESSMENT OF AS-BUILT AND RETROFITTED BUILDINGS: ASSUMPTIONS}

After the code-based assessment of the as-built buildings and the design of their retrofit, a reassessment of these buildings has been performed, as explained in this section. This further phase of 
assessment is aimed at the evaluation of the "real" seismic capacity of the as-built and retrofitted buildings, explicitly considering the infills contribution, the beam-column joints nonlinear behaviour, and the limited displacement capacity of columns potentially subjected to shear failures (see section 4.1). To this end, damage states definition according to EMS-98 macro-seismic scale [17] has been adopted instead than code-conforming limit states (see section 4.2).

\subsection{Modelling assumption}

A lumped plasticity approach has been used for RC members by means of zero-length elements in OpenSees located at the ends of each beam/column element in series with elastic BeamColumn elements (see Figure 10), as for the "code-based assessment" phase.

For member with plain bars, the flexural (bending moment, $\mathrm{M}$ - versus - chord rotation, $\theta$ ) response of beams and columns has been modelled by means of the (quadri-linear) proposal by [22], as already explained in section 3.1. In addition, for the as-built buildings, a pre-classification of each RC member has been performed to a-priori identify its failure mode (i.e., flexural element, F; flexure-shear element, FS; purely-shear element, S), by comparing plastic shear load and shear strength, the latter calculated according to [5]'s shear strength model. When FS or S elements were detected, the relevant flexural moment-chord rotation relationship shown in Figure 10 has been modified, according to [2], by limiting the element deformation capacity according to [6]'s proposal for shear critical RC columns. For the GLD-building, only some interior columns at lower stories resulted to be FSelements. In the case of OSD-building, almost all columns at the first floor (except than column belonging to the exterior transverse frames) resulted FS-elements. In the retrofitted buildings for both the adopted possible strategies ("A" and "B"), it is assumed that the shear failures of these elements have been solved, with a proper technique (e.g., by mean of localized steel cages or FRP fabrics), so that the shear strength of each element becomes higher than its plastic shear load. In such a hypothesis, all the elements in the retrofitted buildings have been assumed as "ductile" ("F" failure mode) with their relevant displacement capacity.

For members with deformed bars, namely for columns interested by RC jacketing (in the case of Strategy "B"), the nonlinear flexural response is modelled by means of the proposal by [39], as commented in section 3.1. Since model by [39] is used only for RC jacketed members, no further modifications are needed to account for any eventual shear failures. In fact, for each jacketed element, a proper number of stirrups can be used to prevent shear failures and ensure its ductile behavior.

Nonlinear response of beam-column joints has been modelled, too (see Figure 10). A zero-length rotational spring has been introduced in the numerical modelling at each beam-column centreline and rigid offset spreading within the joint panel have been modelled at the ends of the beams/columns. The joint moment $\left(\mathrm{M}_{\mathrm{j}}\right)$ - shear strain $\left(\gamma_{\mathrm{j}}\right)$ response depends on the joint typology. The model proposed by [7] is adopted for exterior joints. For interior joints, the joint shear strain values proposed by [40] and the joint shear strength proposed by [41] have been used. For further details, see [7]. As for shear failures in columns, also for joints, it is assumed that, in the retrofitted buildings, the potential shear failure of these elements will be completely solved by means of proper strategies (e.g., by means of pre-stressed steel strips or FRP fabric in the joint core) in both the possible strategies (" $\mathrm{A}$ " and " $\mathrm{B}$ "), so that the beam-column joints become simple elastic elements.

About infill panels, two diagonal (concentric) compressive-only resisting struts (one per loading direction, as shown in Figure 10) have been implemented in each bay (with truss element of OpenSees library). [28]'s (tri-linear) model has been adopted herein: the corresponding axial load-axial strain $\left(\mathrm{N}_{\mathrm{w}}-\varepsilon_{\mathrm{W}}\right)$ response have been implemented with a Hysteretic uniaxial material (see Figure 10) for each truss element. Additionally, [42]'s reduction coefficients of infill lateral strength and stiffness have been used when openings are present.

Lastly, P-Delta effect are considered. 


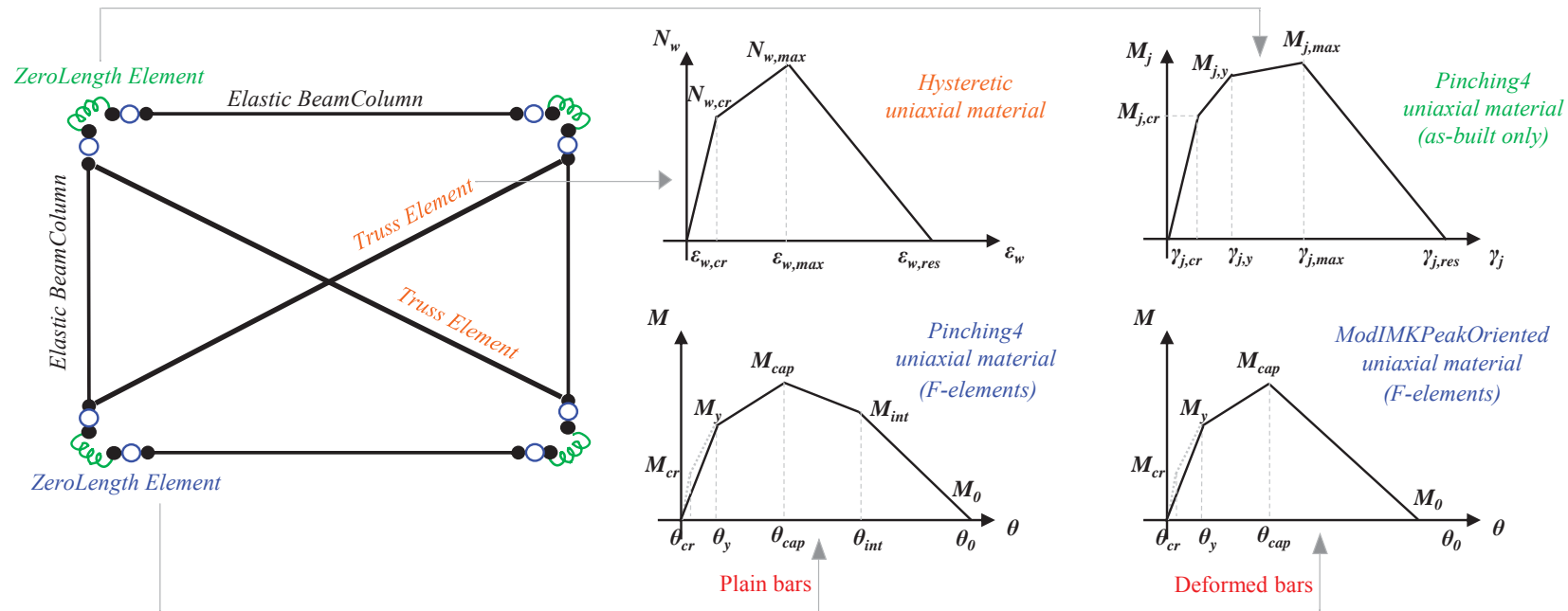

Figure 10: Schematic view of the modelling strategy adopted for each bay for the "real" assessment approach

\subsection{Damage States definitions}

A key issue for the assessment of the "real" seismic capacity is the definition of Damage States (DSs) for the investigated buildings. Two aspects should be considered for these buildings, in agreement with [17]'s definition Table 2), namely:

- the damage to infill panels, generally significantly affecting the relevant repair costs in the aftermath of seismic events ([12]-[14]);

- the damage to RC components (beams/columns and joints).

Therefore, each DS can be achieved due to the achievement of a certain damage level in RC members or in infill panels. The achievement of DS1, DS2, and DS3 due to infills is defined herein according to [43], namely when the interstory drift ratio (IDR) reaches the median IDR capacity at each DS (see Figure 11). In this study, the achievement of DS1, DS2, and, DS3 is also associated to the achievement of the first cracking, the first yielding and the first peak load, respectively, in one element among beams, columns and beam-column joints. However, damage to infills, from light cracking to severe damage, generally condition the achievement of DS1 to DS3 in infilled RC buildings [44], as in the present applications.

\begin{tabular}{|c|c|c|}
\hline DS & EMS-98 [17] & Adopted in this study \\
\hline DS1 & Negligible to slight damage & $\min \left\{\begin{array}{c}\mathrm{IDR}_{\text {infills,DS1 }} \\
\text { RC beam/column/joint cracking }\end{array}\right.$ \\
\hline DS2 & Moderate damage & $\min \left\{\begin{array}{c}\text { IDR }_{\text {infills,DS2 }} \\
\text { RC beam/column/joint yielding/pre }- \text { peak }\end{array}\right.$ \\
\hline DS3 & Substantially to heavy damage & $\min \left\{\begin{array}{c}\text { IDR }_{\text {infills,DS3 }} \\
\text { RC beam/column/joint peak }\end{array}\right.$ \\
\hline DS4 & Very heavy damage & $\begin{array}{l}\mathrm{RC} \text { beam/column zero-load or beam-column joint } \\
\text { residual strenght }\end{array}$ \\
\hline DS5 & Collapse & $\begin{array}{l}\mathrm{RC} \text { beam/column zero-load (if "FS") } \\
\text { or } \mathrm{V}_{\text {base }}=0\end{array}$ \\
\hline
\end{tabular}

Table 2. Adopted DSs definition for infills and RC members and comparison with EMS-98 macro-seismic scale

DS4 and DS5 are achieved due to damage to RC members only, since, at those DSs, infill panels should be already totally damaged. In this study, in agreement with [44], it is assumed that DS4 is achieved when a beam or a column completely losses its lateral load capacity or a beam-column joint 
reaches its residual capacity. When this condition occurs in FS-elements, it is assumed that DS5 also occurs (contemporary to DS4), since, when a shear-critical element losses its lateral load capacity, it is also characterized by the onset of its axial-load failure, which reasonably leads to the collapse of, at least, a part of the building. DS5 is anyway reached when the building base shear becomes null. It is worth noting that the definition of DS4 and DS5 still deserves further investigations in future research efforts.
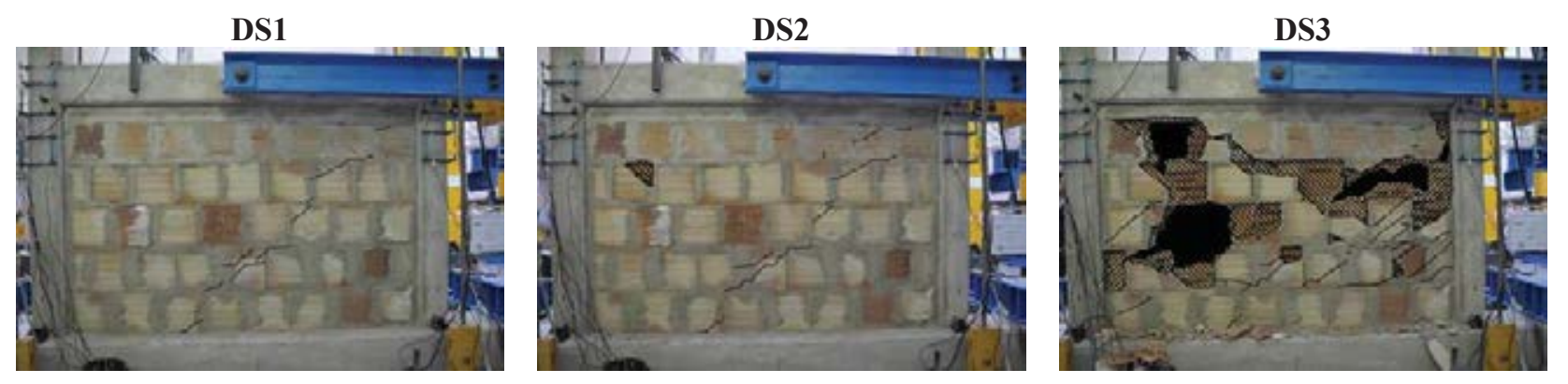

Figure 11: Example of damage state evolution for a masonry infilled frame for the experimental test "DIST Unina" performed at the University of Naples Federico II, adapted by [43].

\section{RE-ASSESSMENT OF AS-BUILT AND RETROFITTED BUILDINGS: RESULTS}

Based on the assumptions explained in section 4, in this section, the SPO curves of the as-built and retrofitted buildings are shown (section 5.1), along with the simplified Incremental Dynamic Analysis (IDA) curves obtained by means of SPO2IDA tool [16] in terms of spectral pseudoacceleration $\mathrm{Sa}(\mathrm{T})$ (section 5.2). Starting from $\mathrm{S}_{\mathrm{a}}(\mathrm{T})$ ), and assuming the spectral shape suggested by [15] for the Italian country, the corresponding PGA capacity values are obtained and fragility curves in PGA at each DS are finally shown in section 5.3. A preliminary comparison among the as-built and the retrofitted buildings is also performed in terms of Expected Annual Losses (EAL) (section 5.4).

\subsection{SPO curves}

SPO analyses have been performed for each case-study building separately in longitudinal (X) and transverse $(Z)$ direction. Two lateral load distributions have been applied, as already explained in section 3. Resulting SPO curves - in terms of base shear versus $\Delta_{\text {top }}$ - and their comparison are shown in Figure 12, grouped depending on the design typology and loading direction, for the as-built and the retrofitted buildings.

It can be noted that SPO curves related to the two as-built buildings are quite similar to each other, even if, as expected, OSD presents higher base shear values and displacement capacity of GLD in the longitudinal direction, as already highlighted in section 3. It can be noted that the "Uniform" distribution leads to higher base shear values. Additionally, the most important comparison can be performed by analysing the SPO curves related to the as-built conditions and Strategy " $A$ " case. It can be observed that the SPO curves do not significantly change when Strategy " $A$ " is adopted, except than (slightly) in the softening branch, since FS-elements in the as-built buildings (when involved in the collapse mechanism) present a stiffer softening branch and a lower displacement capacity than the "corresponding" F-elements in Strategy "A". On the contrary, when RC jacketing are used, obviously, the SPO curves significantly change, incrementing their base shear values and displacement capacity. A very important increment in ductility capacity is also due to the global collapse mechanisms that generally characterise these buildings when the Strategy "B" is adopted. 

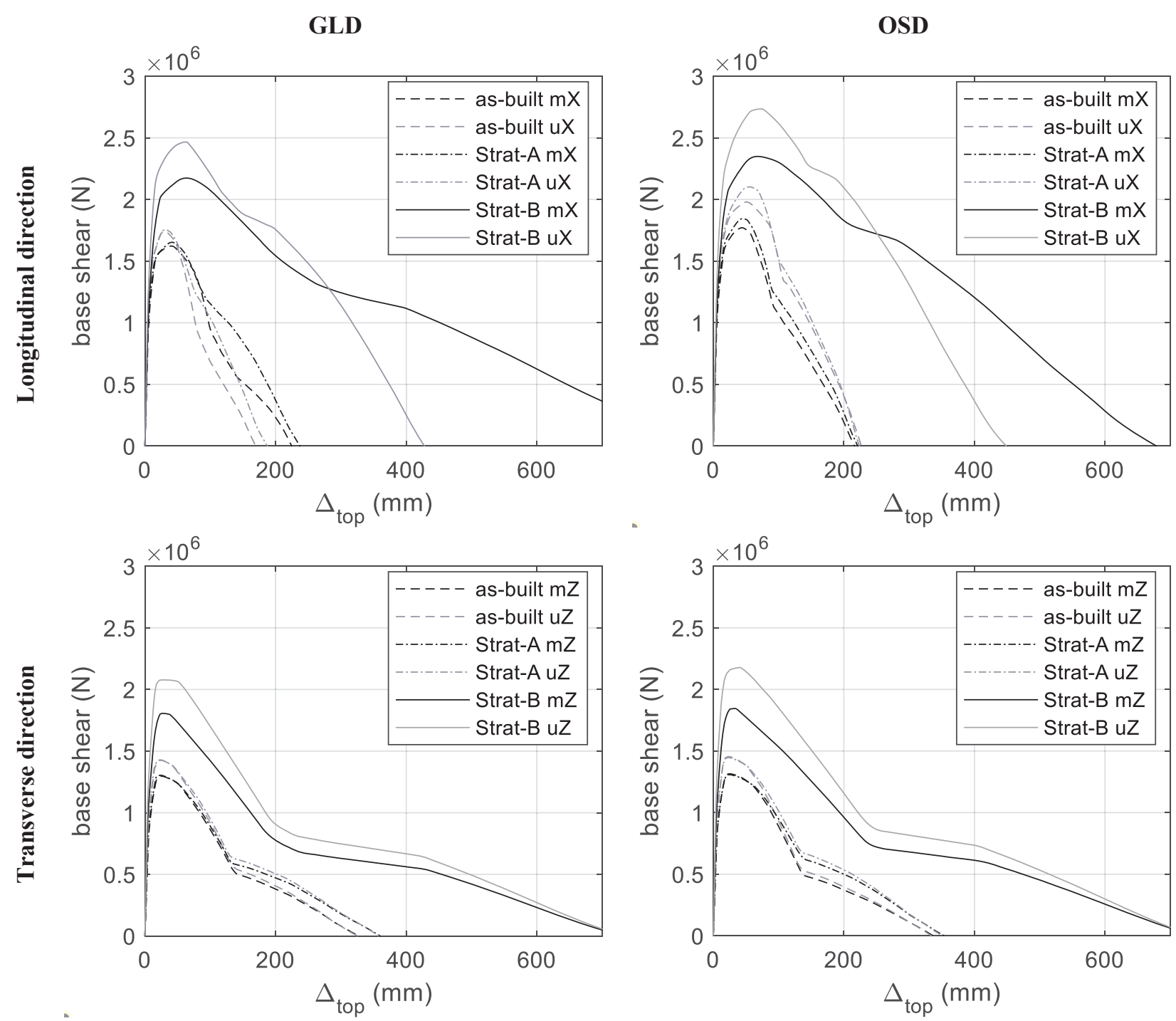

Figure 12: Comparison of SPO curves

\subsection{Simplified IDA curves}

SPO curves are obviously related to a multi-degree-of-freedom (MDOF) system. SPO curve' abscissa and ordinates can be divided by the first mode participation factor $(\Gamma)$ of the building, in each considered direction, to obtain the capacity curve (CC) of the equivalent SDOF system [32]. Then, each CC is multi-linearized to take in due account the strength and stiffness contribution of infill panels. Nevertheless, a zero-strength residual branch is introduced, whereas the softening branch is defined based on an energy-equivalent approach between the peak load and the zero-lateral load point on the pushover curve. As a result, four-branch capacity curves are obtained for each analysed building.

Starting from each quadri-linear CC, the related Incremental Dynamic Analysis (IDA) curve have been derived thanks to the well-known SPO2IDA tool by [16], which provides the relationship between the selected engineering demand parameter $(e d p)$ and the seismic hazard intensity measure (IM). To apply the SPO2IDA tool, the CC should be first expressed in terms of ductility $(\mu)$ - strength reduction factor $(\mathrm{R})$. The ductility $\mu$ is derived as the ratio between $\mathrm{CC}$ abscissas and yielding displacement. The factor $\mathrm{R}$ is the ratio between $\mathrm{CC}$ ordinates and yielding acceleration. SPO2IDA tool finally provides the IDA in terms of $e d p$ (spectral displacement) versus $I M$ (spectral acceleration). Therefore, given a certain capacity $e d p$, the corresponding $16^{\text {th }}-, 50^{\text {th }}-$, and $84^{\text {th }}$ - percentiles of 
capacity $I M$ can be obtained; alternatively, given a certain $I M$ demand, the corresponding $16^{\text {th }}-, 50^{\text {th }}$ , and $84^{\text {th }}$ - percentiles of demand $e d p$ can be derived. 50th-, $16^{\text {th }}$ - and $84^{\text {th }}$ - percentile IDA curves also allow quantifying the record-to-record variability, which will be used later for the definition of the fragility curves "slope".

GLD
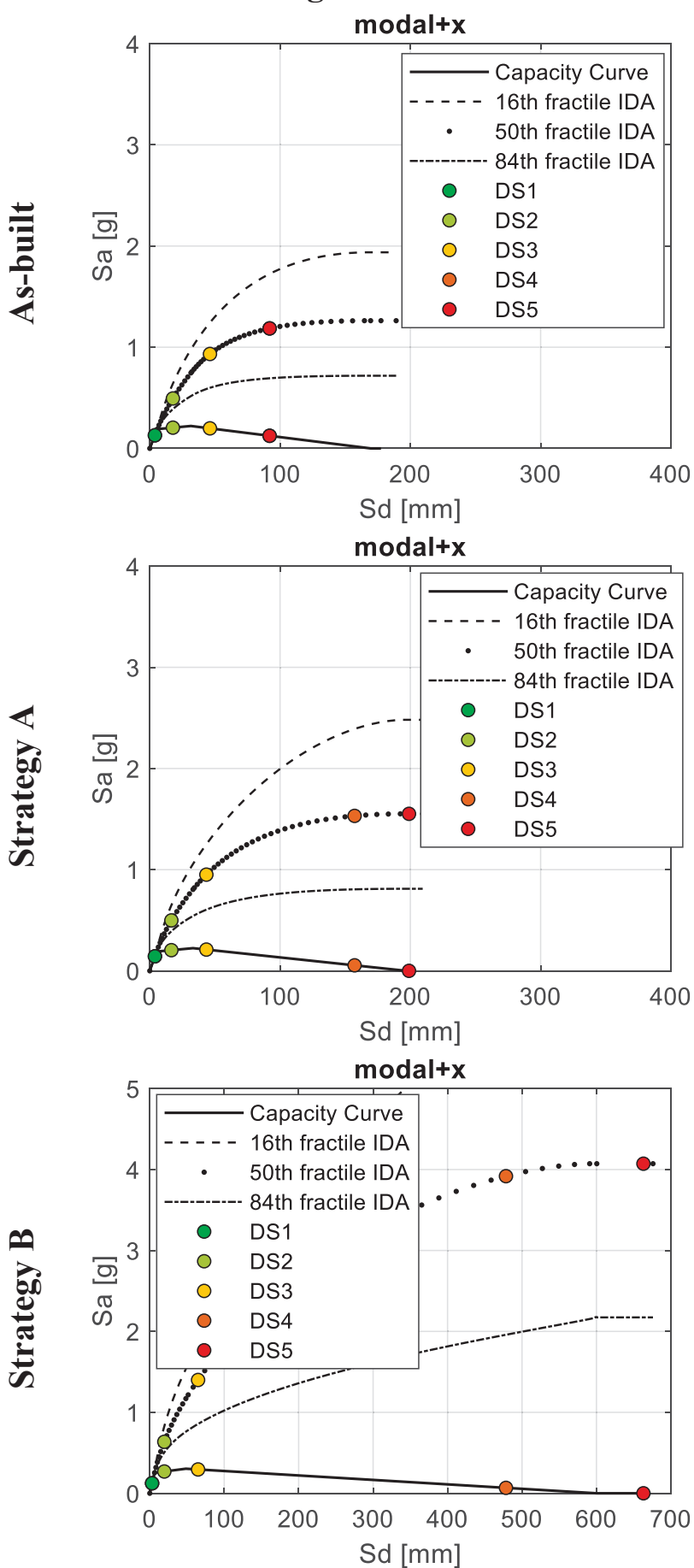

Transverse direction
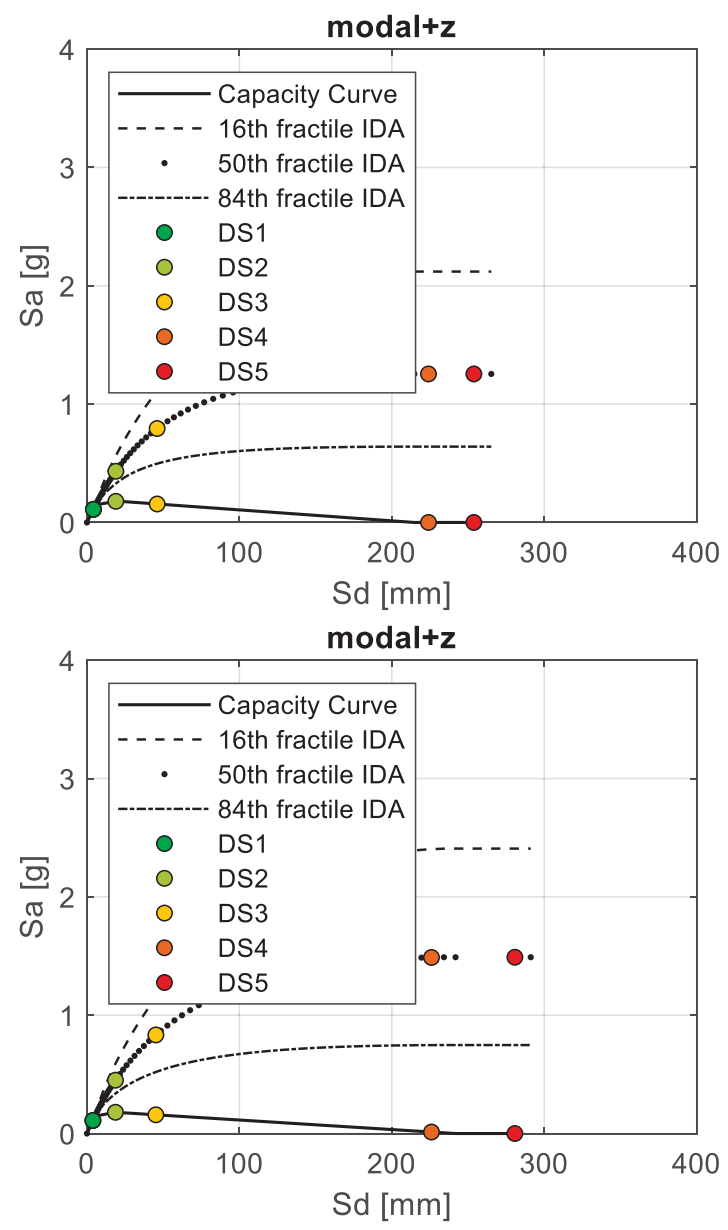

modal+z

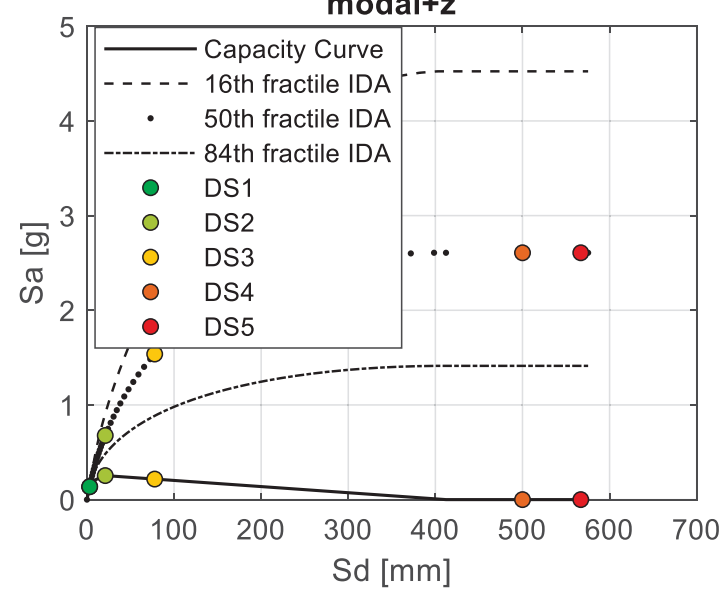

Figure 13: GLD-buildings: Multi-linearized CC, simplified IDA curves and capacity at each DS (only results for "Modal" distribution are reported, for sake of brevity)

Figure 13 and Figure 14 shows the multi-linearized CCs (reported as spectral displacement, $\mathrm{S}_{\mathrm{d}}$, versus spectral pseudo-acceleration, $\mathrm{S}_{\mathrm{a}}$, relationships) and the related (median, $16^{\text {th }}$ and $84^{\text {th }}$ percentiles) IDA 
curves for the case-study buildings, along with the performance points related to the achievement, for the first time, of DS1 to DS5 (as defined in section 4).

OSD
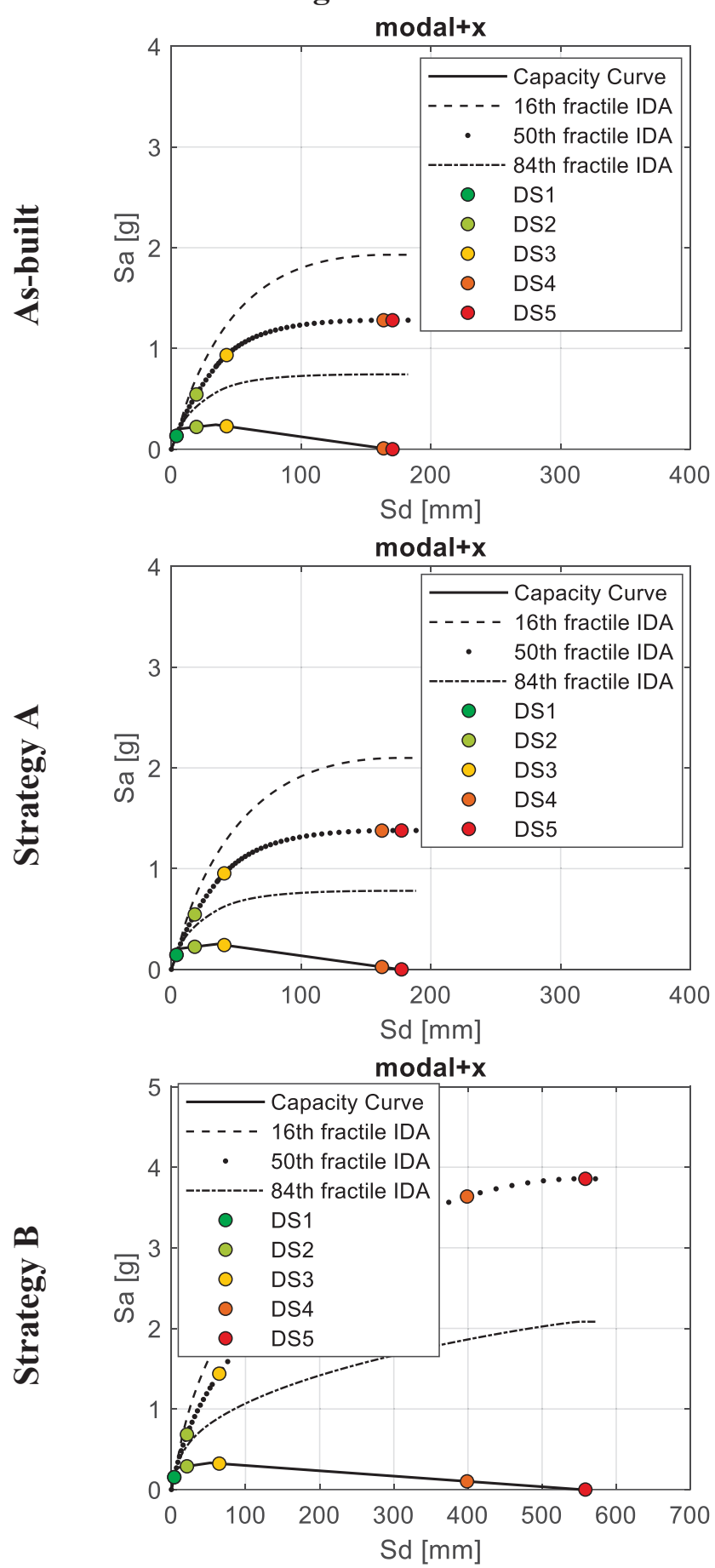

Transverse direction
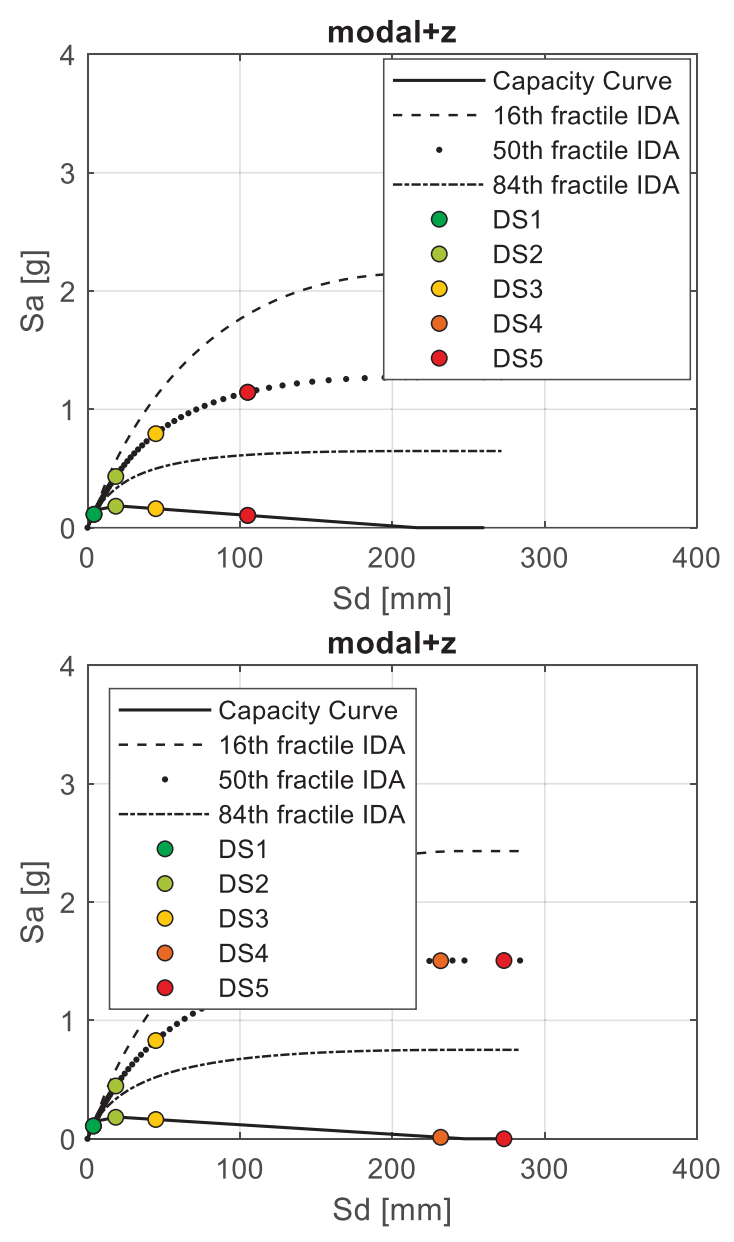

modal+z

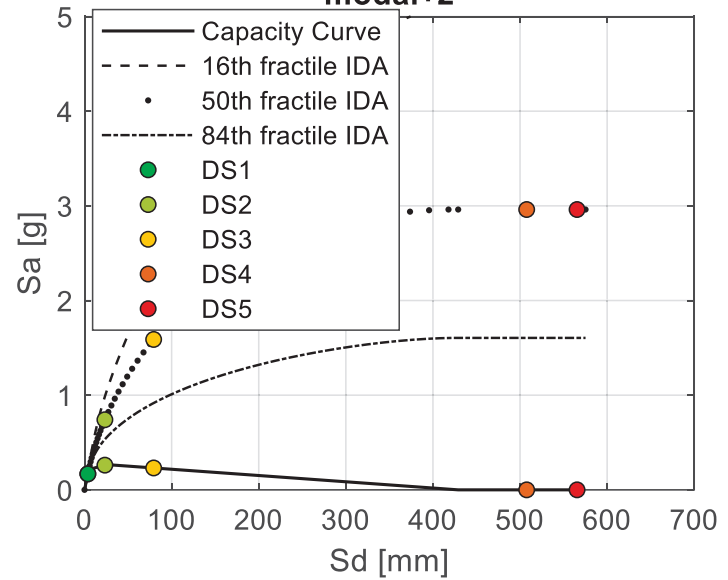

Figure 14: OSD-buildings: Multi-linearized CC, simplified IDA curves and capacity at each DS (only results from "Modal" distribution are reported, for sake of brevity)

It is worth noting that the achievement of DSi (with $\mathrm{i}=1,2,3$ ) for infill panels is assumed to occur when the IDR demand in a panel reaches its median capacity value at that DSi. Additionally, due to the structural regularity of the case-study buildings and the same adopted capacity thresholds for all 
the panels (for sake of simplicity), the achievement of DSi "contemporary" (namely, at the same top displacement level) occurs in all the panels in a storey, in a given direction.

It can be noted that, when Strategy "A" is applied, DS1-to-DS3 remain almost unchanged, whereas displacement capacity at DS4 and DS5 can more significantly increase, especially when their achievement in the as-built buildings was strongly conditioned by the achievement of a null lateral load in shear-critical columns involved in the collapse mechanism.

On the contrary, when Strategy "B" is adopted, seismic capacity at all the DSs improves, above all at DS4 and DS5, but also at less severe DSs. This is mainly due to the increment of lateral stiffness induced by the RC jacketing and to the design approach chosen for this strategy (since it was designed to satisfy the DL limit state).

It is so clear that Strategy "A" and Strategy "B" create a range of minimum and maximum variation of the seismic capacity for these buildings, especially for what concerns the first three DSs, strongly influenced by the infill panels capacity.

\subsection{Fragility curves}

In this section, preliminary fragility curves have been obtained in terms of peak ground acceleration (PGA). To this end, the seismic capacity in terms of $S_{a}$ has been used for each casestudy, along with the spectral shape defined according to Italian code [[15]] for the sites of interest. A single fragility curve (for each DS) has been reported here for each case-study since it represents the minimum capacity between the two main directions and the two selected lateral load distributions (Uniform or Modal). Minimum values of PGA capacities for each case-study are first shown in Table 3. Fragility curves are finally shown and compared to each other in Figure 15. Only record-to-record (RtoR) variability is considered in this study. This is the reason why DS1 fragility curve is a " $Z$ shaped" function, since DS1 generally belongs to the first (elastic) branch of the multi-linearized CC, and no RtoR variability exists in this range of behavior. Further sources of variability should be introduced in future works.

\begin{tabular}{|c|c|c|c|c|c|c|c|c|}
\hline \multirow{2}{*}{ GLD } & \multicolumn{2}{|c|}{ As-built } & \multicolumn{3}{c|}{ Strategy “A” } & \multicolumn{3}{c|}{ Strategy "B" } \\
\cline { 2 - 9 } & $\boldsymbol{\beta}_{\text {RtoR }}$ & $\begin{array}{c}\text { PGA } \\
(\mathbf{g})\end{array}$ & $\boldsymbol{\beta}_{\text {R2R }}$ & $\begin{array}{c}\text { PGA } \\
(\mathbf{g})\end{array}$ & $\begin{array}{c}\text { Retrofitted/ } \\
\text { As-built }\end{array}$ & $\boldsymbol{\beta}_{\text {RtoR }}$ & PGA (g) & $\begin{array}{c}\text { Retrofitted/ } \\
\text { As-built }\end{array}$ \\
\hline DS1 & 0 & 0.05 & 0 & 0.04 & $\mathbf{0 . 9 0}$ & 0 & 0.05 & $\mathbf{1 . 0 7}$ \\
\hline DS2 & 0.24 & 0.18 & 0.24 & 0.18 & $\mathbf{1 . 0 1}$ & 0.23 & 0.28 & $\mathbf{1 . 5 1}$ \\
\hline DS3 & 0.47 & 0.35 & 0.47 & 0.36 & $\mathbf{1 . 0 5}$ & 0.45 & 0.59 & $\mathbf{1 . 7 2}$ \\
\hline DS4 & 0.48 & 0.43 & 0.58 & 0.55 & $\mathbf{1 . 2 6}$ & 0.62 & 1.05 & $\mathbf{2 . 4 1}$ \\
\hline DS5 & 0.48 & 0.43 & 0.58 & 0.55 & $\mathbf{1 . 2 6}$ & 0.62 & 1.05 & $\mathbf{2 . 4 1}$ \\
\hline
\end{tabular}

\begin{tabular}{|c|c|c|c|c|c|c|c|c|}
\hline \multirow{2}{*}{ OSD } & \multicolumn{2}{|c|}{ As-built } & \multicolumn{3}{c|}{ Strategy “A" } & \multicolumn{3}{c|}{ Strategy "B" } \\
\cline { 2 - 10 } & $\boldsymbol{\beta}_{\text {RtoR }}$ & $\begin{array}{c}\text { PGA } \\
(\mathbf{g})\end{array}$ & $\boldsymbol{\beta}_{\text {RtoR }}$ & $\begin{array}{c}\text { PGA } \\
(\mathbf{g})\end{array}$ & $\begin{array}{c}\text { Retrofitted/ } \\
\text { As-built }\end{array}$ & $\boldsymbol{\beta}_{\text {RtoR }}$ & $\begin{array}{c}\text { PGA } \\
\text { (g) }\end{array}$ & $\begin{array}{c}\text { Retrofitted/ } \\
\text { As-built }\end{array}$ \\
\hline DS1 & 0 & 0.04 & 0 & 0.04 & $\mathbf{0 . 9 5}$ & 0 & 0.06 & $\mathbf{1 . 4 1}$ \\
\hline DS2 & 0.27 & 0.19 & 0.28 & 0.19 & $\mathbf{1 . 0 3}$ & 0.23 & 0.30 & $\mathbf{1 . 6 0}$ \\
\hline DS3 & 0.46 & 0.34 & 0.47 & 0.36 & $\mathbf{1 . 0 4}$ & 0.48 & 0.58 & $\mathbf{1 . 7 0}$ \\
\hline DS4 & 0.62 & 0.48 & 0.57 & 0.56 & $\mathbf{1 . 1 7}$ & 0.63 & 1.13 & $\mathbf{2 . 3 7}$ \\
\hline DS5 & 0.62 & 0.48 & 0.57 & 0.56 & $\mathbf{1 . 1 7}$ & 0.63 & 1.13 & $\mathbf{2 . 3 7}$ \\
\hline
\end{tabular}

Table 3: Summary of median PGA capacity and logarithmic standard deviation due to record-to-record variability $\left(\beta_{\text {RtoR }}\right)$ of fragility curves 


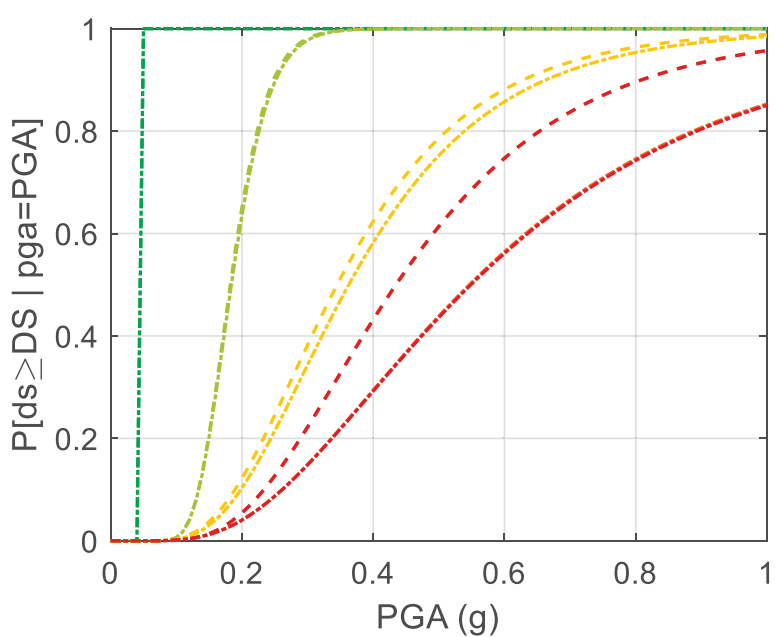

(a)

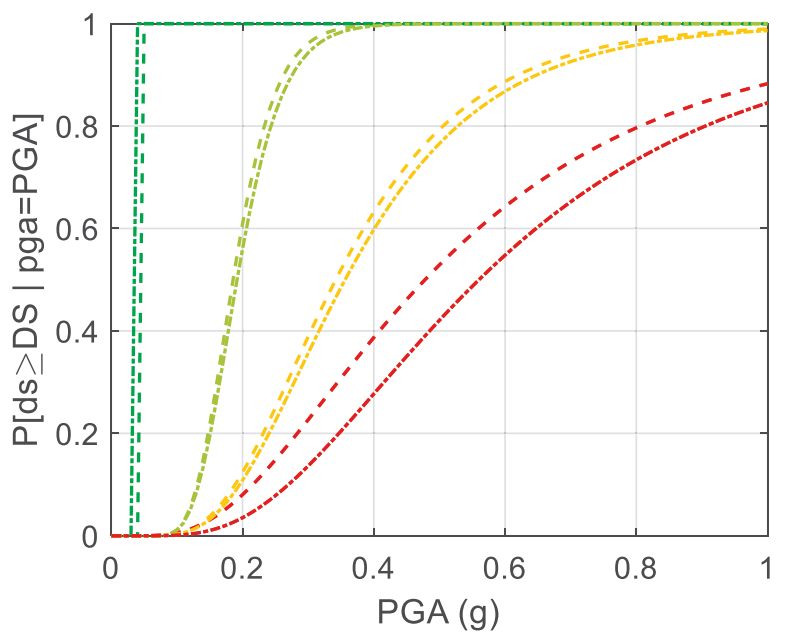

(c)

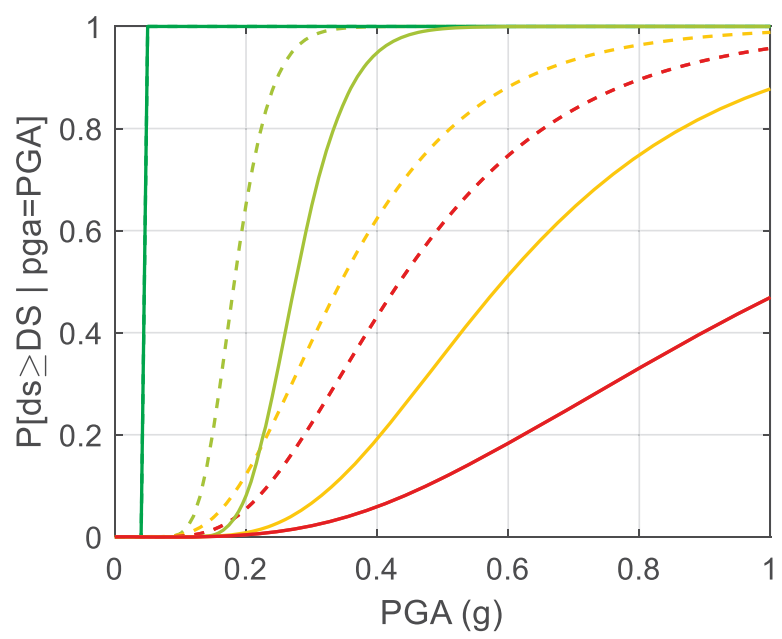

(b)

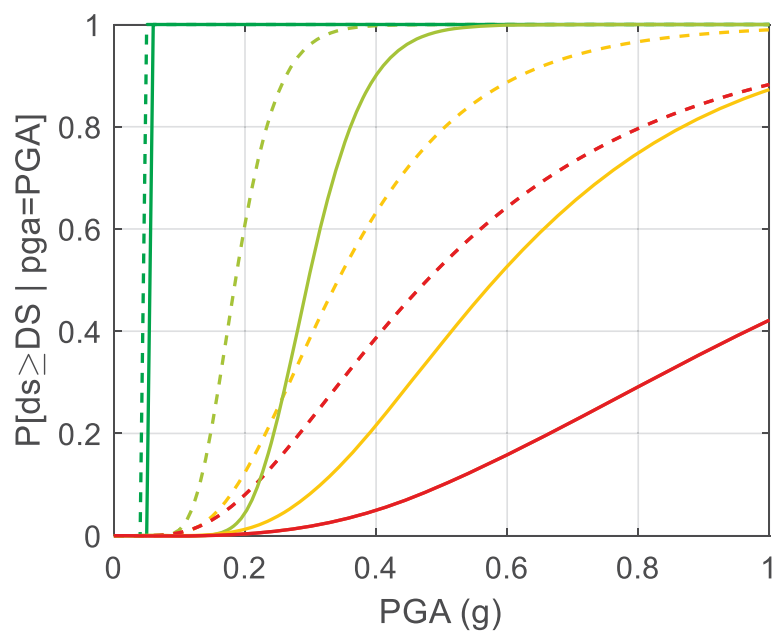

(d)

\begin{tabular}{|c|c|c|}
\hline $\begin{array}{l}----- \text { DS1 - as-built } \\
----- \text { DS2 - as-built } \\
----- \text { DS3 - as-built } \\
----- \text { DS4 - as-built } \\
----- \text { DS5 - as-built }\end{array}$ & $\begin{array}{l}- \\
- \\
-\end{array}$ & $\begin{array}{r}\text { DS1 - Strat. B } \\
\text { DS2 - Strat. B } \\
\text { DS3 - Strat. B } \\
\text { DS4 - Strat. B } \\
\text { DS5 - Strat. B }\end{array}$ \\
\hline
\end{tabular}

Figure 15: Comparisons among fragility curves: GLD (a,b) and OSD (c,d) buildings

The main outcomes from Table 3 and Figure 15 can be summarized as follows:

- When Strategy "A" is applied, the seismic capacity at DS1, DS2, and DS3 changes in terms PGA capacity only slightly (generally very below the $10 \%$ );

- When Strategy "A" is applied, slight changes at DS1 can be ascribable to the small differences in the very first branch of the multi-linearized CC; on the contrary, variation in PGA capacity at DS3 are generally due to some difference in the softening branches of the multi-linearized $\mathrm{CC}$;

- When Strategy "A" is applied, only PGA capacity at DS4 and DS5 is more significantly affected; it can increase from $+17 \%$ (OSD) to $+26 \%$ (GLD), mostly due to the capability to switch off column shear failures (when they resulted shear-critical elements in the as-built buildings); 
- When Strategy "B" is applied, the maximum increment in PGA capacity at DS1 to DS3 can be observed, due to the higher lateral stiffness produced by the columns RC jacketing and the way these jacketings have been designed (namely, to satisfy the DL limit state, see section 3);

- When Strategy "B" is applied, the PGA capacity at DS4 and DS5 increases significantly (more than $100 \%$ ) also thanks to the global collapse mechanism they produce.

A final comment is about the difference in terms of capacity increment assessment obtained in this section and that obtained in a code-based approach (section 3). When safety check and retrofit design are performed in code-based approach, the first joint failure significantly influences the seismic capacity of the as-built building, limiting it to the first shear cracking in the joint panel in a forcebased approach. When shear-critical elements, like joints as well as columns, are analyzed in a displacement-based approach, contrary to what the code prescribes, the assessment results are very different, even in the as-built configurations. Additionally, infill panels are not accounted for in typically code-conforming practice-oriented analyses. As a result, even if Strategy "A" leads to a PGA capacity increment higher than $150 \%$ for GLD and $350 \%$ for OSD (from the first joint shear failure to the first ductile failure) in a code-based approach (section 3), such a high increment cannot be found when a displacement-based safety assessment is performed; in this latter case, the capacity increment ascribable to Strategy "A" is more limited (around $+20 \%$ ), at least for the buildings analysed in this work.

\subsection{Preliminary estimation of EAL}

A final comparison among the as-built and the retrofitted buildings is performed here in terms of mean Expected Annual Losses (EAL), to emphasize the importance of the less severe damage states - and thus of masonry infills which condition the achievement of those DSs - to the seismic loss estimation. It is worth remembering that EAL represents the average amount of money (generally expressed as a percentage of the total reconstruction cost) to be spent per year to repair damage due to seismic events during the building lifetime.

First, for each DS, the expected seismic losses, expressed as a percentage of the total reconstruction cost $(\% \mathrm{CR})$, should be defined. A clear association between $\% \mathrm{CR}$ and limit states defined according to Italian [15] and Eurocode 8 [18] can be found in [44] and in [46]. In this work, such an association is preliminary based on a previous study by the Authors ([13]-[14]), which considered damage to infills/partitions and services only for the same DSs adopted herein (in particular from DS1 to DS3). Therefore, $4 \%, 15 \%$, and $31 \%$ of the building reconstruction cost has been assumed here at DS1, DS2, and DS3, respectively, only accounting for seismic losses due to infills/partitions and services allocated in within. DS5 is instead a physical collapse for the building and, therefore, it is associated herein to $100 \%$ of the reconstruction cost.

Additionally, the mean annual frequency of exceeding a certain DS $(\lambda)$ can be obtained (as the inverse of the capacity return period at that DS), thus obtaining all the information required to calculate the EAL, as the area underneath the $\lambda-\%$ CR curves (Figure 16). A maximum threshold for $\lambda(10 \%)$ has been preserved in agreement with [46].

Resulting EAL values are finally reported in Table 4. It can be noted that the EAL related to the asbuilt buildings and that related to the adoption of "Strategy A" are technically identical (about 3\% of reduction). This means that, when seismic capacity increment affects the most severe DSs only, no benefits can be gained in terms of seismic losses. On the contrary, the increment in lateral stiffness (produced by Strategy "B") can reduce the EAL of about $20 \%$ for both the case-study buildings. 


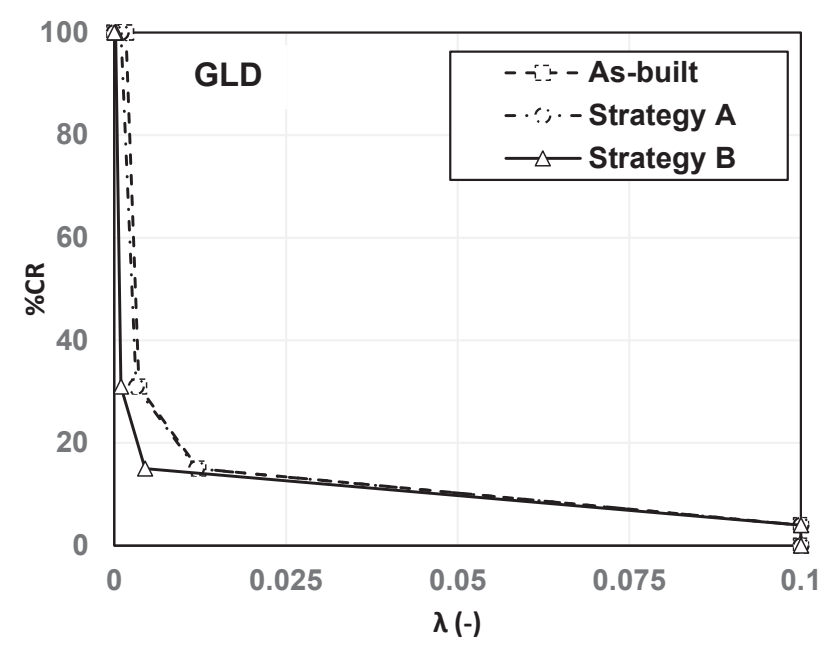

(a)

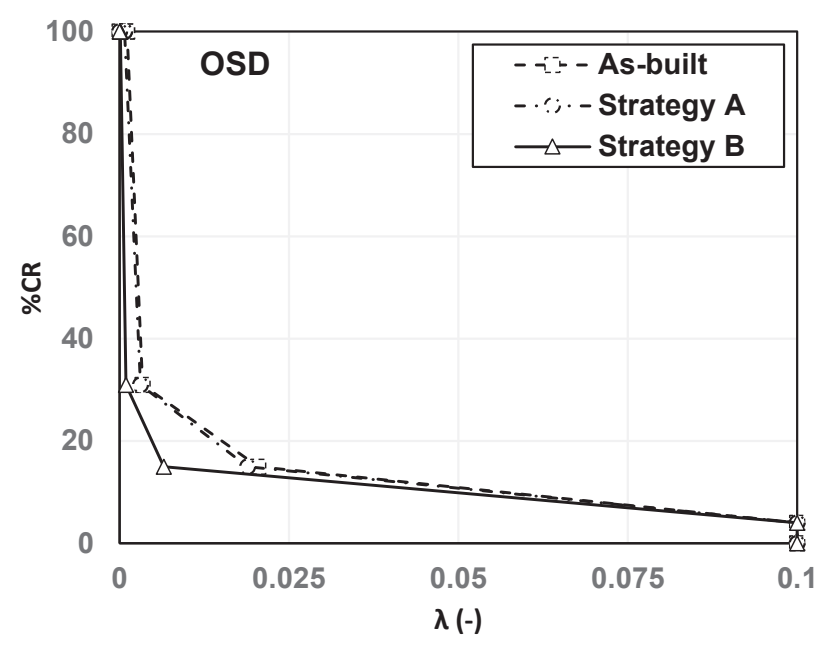

(b)

Figure 16: Percentage of the Reconstruction Cost $(\% \mathrm{CR})$ depending on the mean annual frequency of exceedance each DS $(\lambda)$

\begin{tabular}{|l|c|c|}
\hline EAL (\%) & GLD & OSD \\
\hline As-built & 1.33 & 1.41 \\
\hline Strategy "A" & $1.28(-3 \%)$ & $1.36(-3 \%)$ \\
\hline Strategy "B" & $1.06(-20 \%)$ & $1.08(-21 \%)$ \\
\hline
\end{tabular}

Table 4: Expected annual losses, EAL (in grey, its percentage variation with respect to the relevant as-built building).

\section{CONCLUSIONS}

A preliminary seismic analysis of two case-study low-standard RC buildings has been presented, based on static nonlinear analyses. The investigated case-study structures are 4-storey buildings representative of Italian pre-70 residential buildings, designed for gravity loads only (GLD) or according to obsolete seismic design (OSD). First, they have been assessed in a code-based approach according to the current Italian code [15], namely without infills (as typical in practice) and modelling nonlinear flexural response of beams and columns only, whereas columns/joints shear failures have been detected in post-processing (in a force-based safety check). Then, based on the as-built assessment outcomes, the retrofit phase has been designed by means of two alternative strategies, representing two boundary conditions for the lateral stiffness modification of the buildings:

1. Strategy "A": the complete resolution of all the shear failures (in columns or joints), if any, at Life Safety limit state;

2. Strategy "B": the reduction of the displacement demand by means of RC column jacketings, designed at the Damage Limitation limit state, along with the resolution of shear failures at LS limit state.

Then, both the as-built and retrofitted building configurations have been modelled and analysed explicitly considering the presence of infills and shear-critical elements, including beam-column joints. Fragility curves have been obtained at different Damage States (DSs) according to European Macroseismic Scale EMS-98, from DS1 to DS5, considering record-to-record variability, and compared to each other. DSs from 1 to 3 were significantly affected by the infill presence; they were always achieved due to the achievement of the relevant drift capacity in infill panels.

The following conclusions can be drawn: 
- when Strategy "A" is applied, the seismic capacity at DS1, DS2, and DS3 changes only slightly (generally very below the $10 \%$ in terms PGA capacity);

- when Strategy "A" is applied, only seismic capacity at DS4-5 is more significantly affected; PGA capacity at DS4 and DS5 it can increase from $+17 \%$ (OSD) to $+26 \%$ (GLD), mostly due to the capability to switch off column shear failures (when they resulted shear-critical elements in the as-built buildings);

- when Strategy "B" is applied, the maximum increment in PGA capacity at DS1 to DS3 can be observed, due to the higher lateral stiffness produced by the columns RC jacketing and the way these jacketings have been designed (namely, to satisfy the DL limit state);

- when Strategy "B" is applied, the PGA capacity at DS4 and DS5 increases significantly (more than $100 \%$ ) also thanks to the global collapse mechanism they produce;

- if mean Expected Annual Losses (EAL) are evaluated, it can be noted that, when seismic capacity increment affects the most severe DSs only (as for Strategy "A"), no benefits can be gained in terms of economic losses (only 3\% reduction); on the contrary, the increment in lateral stiffness produced by Strategy "B" can reduce the EAL of about $20 \%$ for both the casestudy buildings.

It is worth noting that the present study analyses only two case-studies in a static nonlinear analyses approach and only considering record-to-record variability to obtain fragility curves. Other casestudies and sources of variability should be considered in future works, also in the context of nonlinear dynamic analyses. Additionally, the modelling strategies and DSs definition adopted herein will be deeper investigated, both about a more detailed definition of DS4 and DS5 (a topic still controversial in the literature), and about the modelling of further key shear-critical phenomena (above all involving beam-column joints), such as the joint axial load failure in as-built buildings (herein neglected). Lastly, in this study, infill panels have been considered to be identical in the as-built and in retrofitted buildings. Nevertheless, such an aspect could be modified in future works to consider the possibility of a change in infill typology to address energy-efficiency requirements, at least when invasive strategies (like Strategy "B") are implemented.

\section{ACKNOWLEDGEMENTS}

This work was developed under the support of ReLUIS-DPC 2019-2021 funded by the Italian Department of Civil Protection (DPC), and PON-AIM Ricerca e Innovazione 2014-2020 - Fondo Sociale Europeo, Azione I.2, "Smart, Secure and Inclusive Communities. These supports are gratefully acknowledged.

\section{REFERENCES}

[1] Shoraka Baradaran, M. (2013). Collapse assessment of concrete buildings: an application to non-ductile reinforced concrete moment frames (Doctoral dissertation, University of British Columbia).

[2] Ricci, P., Manfredi, V., Noto, F., Terrenzi, M., De Risi, M. T., Di Domenico, M., Camata, G., Franchin, P., Masi, A., Mollaioli, F., Spacone, E., Verderame, G.M. (2019). RINTC-e: Towards seismic risk assessment of existing residential reinforced concrete buildings in Italy. In Proceedings of the 7th ECCOMAS Thematic Conference on Computational Methods in Structural Dynamics and Earthquake Engineering, Crete, Greece (pp. 24-26). 
[3] Elwood, K. J., \& Moehle, J. P. (2005). Drift capacity of reinforced concrete columns with light transverse reinforcement. Earthquake Spectra, 21(1), 71-89.

[4] Elwood, K. J., \& Moehle, J. P. (2005). Axial capacity model for shear-damaged columns. ACI Structural Journal-American Concrete Institute, 102(4), 578-587.

[5] Sezen, H., \& Moehle, J. P. (2004). Shear strength model for lightly reinforced concrete columns. Journal of structural engineering, 130(11), 1692-1703.

[6] Aslani, H., Miranda, E., 2005. Probabilistic earthquake loss estimation and loss disaggregation in buildings. J. A. Blume Earthquake Engineering Center. Research report n. 157. Stanford, California, United States.

[7] De Risi, M. T., Ricci, P., \& Verderame, G. M. (2017). Modelling exterior unreinforced beamcolumn joints in seismic analysis of non-ductile RC frames. Earthquake Engineering \& Structural Dynamics, 46(6), 899-923.

[8] Liel, A. B., \& Deierlein, G. G. (2008). Assessing the collapse risk of California's existing reinforced concrete frame structures: metrics for seismic safety decisions (Vol. 69, No. 05).

[9] Pampanin, 2017. Valutazione della vulnerabilita', classificazione sismica, strategie di rinforzo e riduzione del rischio sismico di edifici esistenti in calcestruzzo armato parte iii: strategie e tecniche di rinforzo, Structural 210 - settembre/ottobre 2017 - paper 28- ISSN 2282-3794 DOI 10.12917/Stru213.28

[10] Giovinazzi, S., \& Pampanin, S. (2017). Simplified Approaches for the Seismic Risk Rating of Reinforced Concrete Buildings and the Selection of Retrofit Strategies.

[11] Cardone, D., Gesualdi, G., \& Perrone, G. (2019). Cost-benefit analysis of alternative retrofit strategies for RC frame buildings. Journal of Earthquake Engineering, 23(2), 208-241.

[12] Del Vecchio, C., Di Ludovico, M., \& Prota, A. (2019). Repair costs of RC building components: from actual data analysis to calibrated consequence functions. Earthquake Spectra.

[13] De Risi, M. T., Del Gaudio, C., \& Verderame, G. M. (2020). A component-level methodology to evaluate the seismic repair costs of infills and services for Italian RC buildings. Bulletin of Earthquake Engineering, 18(14), 6533-6570.

[14] Del Gaudio, C., De Risi, M. T., \& Verderame, G. M. (2021). Seismic Loss Prediction for Infilled RC Buildings via Simplified Analytical Method. Journal of Earthquake Engineering, $1-34$.

[15] D.M. 2018, Aggiornamento delle «Norme Tecniche per le Costruzioni» - D.M. 17/1/18. (in Italian)

[16] Vamvatsikos, D., \& Allin Cornell, C. (2006). Direct estimation of the seismic demand and capacity of oscillators with multi-linear static pushovers through IDA. Earthquake engineering \& structural dynamics, 35(9), 1097-1117.

[17] Grunthal G (1998) Cahiers du Centre Europeen de Geodynamique et de Seismologie: volume 15-European Macroseismic Scale 1998. European Center for Geodynamics and Seismology, Luxembourg

[18] CEN 2004, Eurocode 8: Design of structures for earthquake resistance - Part 1 : General rules, seismic actions and rules for buildings, European Committee for Standardization, Ref. N. EN 1998-1 :2004 
[19] Verderame G.M., Polese M., Mariniello C., Manfredi G., (2010). A simulated design procedure for the assessment of seismic capacity of existing reinforced concrete buildings. Advances in Engineering Software, 41(2), 323-335.

[20] Verderame G.M., Ricci P., Esposito M., Manfredi G., (2012). STIL v1.0 - Software per la caratterizzazione delle proprietà meccaniche degli acciai da c.a. tra il 1950 e il 2000. ReLUIS, http://www.reluis.it/

[21] R.D. Regio Decreto Legge n. 2229 del 16/11/1939. Norme per la esecuzione delle opere in conglomerate cementizio semplice od armato. G.U. n. 92 del 18/04/1940 (in Italian)

[22] Verderame, G. M., \& Ricci, P. (2018). An empirical approach for nonlinear modelling and deformation capacity assessment of RC columns with plain bars. Engineering Structures, 176, 539-554.

[23] Bal I.E., Crowley H., Pinho R., Gulay F.G., 2007. Structural characteristics of Turkish RC building stock in Northern Marmara region for loss assessment applications. ROSE Research Report No. 2007/03, IUSS Press, Pavia, Italy.

[24] R.D. Regio Decreto Legge n. 2105 del 22/11/1937 - "Norme tecniche di edilizia con speciali prescrizioni per le località colpite dai terremoti”, G.U. n. 298 del 27/12/1937. (in Italian)

[25] D.M. L.1684/1962 Legge 25 novembre 1962, n. 1684, Gazzetta Ufficiale 22 dicembre 1684, n. 326, Provvedimenti per l'edilizia, con particolari prescrizioni per le zone sismiche. (in Italian)

[26] Del Gaudio, C., De Risi, M. T., Scala, S. A., \& Verderame, G. M. (2020). Seismic loss estimation in pre-1970 residential RC buildings: the role of infills and services in low-mid rise case-studies. Frontiers in Built Environment, 6, 188.

[27] Masi, A., Digrisolo, A., and Santarsiero, G. (2014). Concrete strength variability in Italian RC buildings: analysis of a large database of core tests. In Applied Mechanics and Materials (Vol. 597, pp. 283-290). Trans Tech Publications Ltd.

[28] De Risi M.T., Del Gaudio C., Ricci P., Verderame G.M., 2018. In-plane behaviour and damage assessment of masonry infills with hollow clay bricks in RC frames. Engineering Structures, $168,257-275$.

[29] Mucedero, G., Perrone, D., \& Monteiro, R. (2021). Nonlinear static characterisation of masonry-infilled RC building portfolios accounting for variability of infill properties. Bulletin of Earthquake Engineering, 1-45.

[30] CEN (2005) EN 1998-3-1-4 Eurocode 8, Design of Structures for Earthquake Resistance, Part 3, Assessment and Retrofitting of Buildings. European Committee for Standardization.

[31] McKenna, F. 2011. OpenSees: A framework for earthquake engineering simulation. Computing in Science \& Engineering 13 (4): 58-66. doi: 10.1109/MCSE.2011.66.

[32] Fajfar, P., 1999, Capacity spectrum method based on inelastic demand spectra, Earthquake Engineering and Structural Dynamics 28: 979-993.

[33] Biskinis, Dionysis, and Michael N. Fardis. "Deformations at flexural yielding of members with continuous or lap-spliced bars." Structural concrete 11.3 (2010): 127-138.

[34] Circolare 21 gennaio 2019, n. 7 C.S.LL.PP. Istruzioni per l'applicazione dell'«Aggiornamento delle "Norme tecniche per le costruzioni"» di cui al decreto ministeriale 17 gennaio 2018. GU n.35 del 11-2-2019 - Suppl. Ordinario n. 5. (in Italian) 
[35] Priestley MJN. Myths and fallacies in earthquake engineering, revisited. The Mallet Milne Lecture. IUSS Press: Pavia, Italy, 2003.

[36] Biskinis DE, Roupakias GK, Fardis MN (2004) Degradation of shear strength of reinforced concrete members with inelastic cyclic displacements. Struct J 101(6):773-783

[37] Vidic, T., Fajfar, P., \& Fischinger, M. (1994). Consistent inelastic design spectra: strength and displacement. Earthquake Engineering \& Structural Dynamics, 23(5), 507-521.

[38] Frascadore, R., Di Ludovico, M., Prota, A., Verderame, G. M., Manfredi, G., Dolce, M., \& Cosenza, E. (2015). Local strengthening of reinforced concrete structures as a strategy for seismic risk mitigation at regional scale. Earthquake Spectra, 31(2), 1083-1102.

[39] Haselton C, Liel A, Taylor SL and Deierlein GG. Beam-Column Element Model Calibrated for Predicting Flexural Response Leading to Global Collapse of RC Frame Buildings. Pacific Earthquake Engineering Research Center 2007/03, University of California at Berkeley, 2007.

[40] Celik OC and Ellingwood BR. Modeling Beam-Column Joints in Fragility Assessment of Gravity Load Designed Reinforced Concrete Frames. Journal of Earthquake Engineering, 2008, 12: 357-381.

[41] Jeon JS, Shafieezadeh A and DesRoches R. Statistical models for shear strength of RC beamcolumn joints using machine-learning techniques. Earthquake Engineering \& Structural Dynamics, 2014, 43(14): 2075-2095.

[42] Decanini, L. D., Liberatore, L., and Mollaioli, F. (2014). Strength and stiffness reduction factors for infilled frames with openings. Earthquake Engineering and Engineering Vibration, 13(3), 437-454.

[43] Del Gaudio, M.T. De Risi, C., Ricci, P., Verderame, G. M. (2019). Empirical drift-fragility functions and loss estimation for infills in reinforced concrete frames under seismic loading. Bulletin of Earthquake Engineering https://doi.org/10.1007/s10518-018-0501-y.

[44] Del Gaudio, C., Ricci, P., Verderame, G. M., \& Manfredi, G. (2015). Development and urbanscale application of a simplified method for seismic fragility assessment of RC buildings. Engineering Structures, 91, 40-57.

[45] Cosenza, E., Del Vecchio, C., Di Ludovico, M., Dolce, M., Moroni, C., Prota, A., \& Renzi, E. (2018). The Italian guidelines for seismic risk classification of constructions: technical principles and validation. Bulletin of Earthquake Engineering, 16(12), 5905-5935.

[46] D. M. 58 28/02/2017 Allegato A: linee guida per la classificazione del rischio sismico delle costruzioni. Italian Ministry of Infrastructures and Transport, Italy. http://www.mit.gov. it/normativa/decreto-ministeriale-numero-58-del-28022 017 (in Italian). 